\title{
Chemical characterization of ambient aerosol collected during the southwest monsoon and intermonsoon seasons over the Arabian Sea: Anions and cations
}

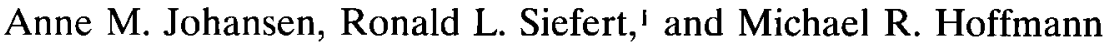 \\ Environmental Engineering Science, W. M. Keck Laboratories, Californı Instıtute of Technology, Pasadena
}

\begin{abstract}
Ambient aerosol samples were collected over the northern Indian Ocean during two 1 month-long research cruises (German R/V Meteor) that took place during the intermonsoon (May) and SW monsoon (July/August) of 1995. A high volume and two small volume collectors were used to collect samples, which were subsequently analyzed for ferrous iron, 32 elements, and anions and cations. The present paper focuses on the bulk aerosol material, the ions, while utilizing some of the trace metal data that were presented in more detail in our previous paper [Siefert et al., 1999]. Data are analyzed and interpreted with the aid of principal component and multiple linear regression analyses. Intermonsoon samples were strongly influenced by continental material, both of crustal and anthropogenic origin. The crustal component $(24.5 \pm 13 \%$ of the total suspended particulate mass (TSP), $\left.6.0 \pm 4.4 \mu \mathrm{g} \mathrm{m}^{-3}\right)$ contained $3.2 \%$ gypsum $\left(\mathrm{CaSO}_{4}\right)$. While more than half of the TSP $\left(21.2 \pm 9.6 \mu \mathrm{g} \mathrm{m}^{-3}\right)$ during the SW monsoon was sea-salt-derived due to the strong winds prevailing during this season, only $1.7 \pm 1.1 \%\left(0.7 \pm 0.4 \mu \mathrm{g} \mathrm{m}^{-3}\right)$ was found to be of crustal origin. Sulfate $\left(\mathrm{SO}_{4}^{2-}\right)$ sources were determined and quantified with linear regression analyses utilizing specific tracers for the independent variables. Lead $(\mathrm{Pb})$ was found to be a more reliable surrogate for anthropogenic $\mathrm{SO}_{4}^{2-}$ compared to nitrate $\left(\mathrm{NO}_{3}^{-}\right)$during the relatively polluted intermonsoon. Soluble calcium $\left(\mathrm{Ca}^{2+}\right)$ served as the tracer for gypsum, and methane sulfonate (MSA) served as the tracer for biogenically derived $\mathrm{SO}_{4}^{2-}$ during both seasons. On the basis of this analysis, $75 \%$ of the non-sea-salt sulfate (NSS-SO $\left.{ }_{4}^{2-}\right)\left(0.8 \pm 0.2 \mu \mathrm{g} \mathrm{m}^{-3}\right.$, representing $\sim 2.4 \%$ of TSP) was found to be of biogenic origin during the SW monsoon with the remaining $25 \%$ of anthropogenic origin. During the intermonsoon, NSS-SO ${ }_{4}^{2-}$ accounted for $2.1 \pm 1.2 \mu \mathrm{g}$ $\mathrm{m}^{-3}(\sim 9.2 \%$ of TSP) and had a composition that was $65 \%$ anthropogenic, $21 \%$ biogenic, and $14 \%$ gypsum-derived. Linear regression analyses revealed that the bio-SO ${ }_{4}^{2-} / \mathrm{MSA}$ weight ratios appear to be consistent with the temperature dependence proposed by Hynes et al. [1986]. In this case the yield of $\mathrm{SO}_{4}^{2-}$ increased relative to MSA with an increase in temperature. Three samples during the SW monsoon, near the coast of Oman, showed lower temperatures, due to coastal upwelling, than the rest of the samples; at $24^{\circ} \mathrm{C}$ the bio-SO ${ }_{4}^{2-} / \mathrm{MSA}$ weight ratio was $6.8 \pm 0.5$. The remainder of the $\mathrm{SW}$ monsoon samples were collected at an average temperature of $27.2^{\circ} \mathrm{C}$, for which the bio-SO ${ }_{4}^{2-} / \mathrm{MSA}$ weight ratio was $13.5 \pm 4.4$. At an average temperature of $28.9^{\circ} \mathrm{C}$ during the intermonsoon, sampling gave a ratio of $17.7 \pm 4.8$. These observations indicate a temperature dependence factor between $24^{\circ}$ and $29^{\circ} \mathrm{C}$ of 2.2 (i.e., a 2.2 increase in the ratio of bio-SO ${ }_{4}^{2-} / \mathrm{MSA}$ with every degree temperature increase). $\mathrm{Cl}^{-}$deficits determined during both seasons appear to indicate that different mechanisms may govern the observed depletion of $\mathrm{Cl}^{-}$in each season.
\end{abstract}

\section{Introduction}

The chemistry of ambient aerosols, which are complex mixtures of minerals, sea salt, and organic compounds and their interaction with gas molecules is still poorly understood [Andreae and Crutzen, 1997; Keene et al., 1998]. Basic information on their detailed composition and ambient reactivity is still needed. The present study is part of a large set of field obser-

\footnotetext{
${ }^{1}$ Now at Chesapeake Biological Laboratory, University of Maryland Center for Environmental Science, Solomons, Maryland.

Copyright 1999 by the American Geophysical Union.

Paper number 1999JD900405.

0148-0227/99/1999JD900405\$09.00
}

vations collected to shed light on the chemical composition of atmospheric aerosol particles in different marine environments. Aerosol samples discussed in this study were initially described in our first paper in this series [Siefert et al., 1999] in terms of their trace metal composition and the labile-Fe(II) concentrations. In this paper, we focus our attention on the bulk aerosol composition.

Non-sea-salt sulfate (NSS-SO ${ }_{4}^{2-}$ ) particles in the submicrometer size range serve as cloud condensation nuclei (CCN) and influence the radiation balance of the atmosphere [Charlson et al., 1987]. Extensive efforts have been focused on elucidation of the chemical and physical processes that lead to $\mathrm{NSS}^{-\mathrm{SO}_{4}^{2-}}$ particle formation from anthropogenic and biogenic sulfur sources. Biogenic sources of sulfur that contribute 
to NSS-SO ${ }_{4}^{2-}$ are particularly important in the marine boundary layer of remote oceanic regions [Andreae et al., 1995; Berresheim et al., 1993; Charlson et al., 1987].

Sea-salt particles may act as seeds for the uptake and oxidation of sulfur gases and deposition of condensable sulfate vapors [Keene et al., 1998; McInnes et al., 1994]. Sea salt may also strongly influence the oxidative properties of aerosol particles in the marine boundary layer through the production of halogen radicals [Fan and Jacob, 1992; Finlayson-Pitts et al., 1989; Graedel and Keene, 1995; Keene et al., 1996; Pszenny et al., 1993; Sander and Crutzen, 1996; Vogt et al., 1996]. These transient radical oxidants may have an effect on biogenically emitted gases known to be the source of sulfate and organic aerosol particles over the oceans.

The primary organosulfur compound emitted to the atmosphere is dimethyl sulfide $\left(\mathrm{CH}_{3} \mathrm{SCH}_{3}, \mathrm{DMS}\right)$ [Bates et al., 1992]. The reactions of DMS with hydroxy radical (OH) and nitrate radical $\left(\mathrm{NO}_{3}\right)$ are the initial steps in a complex chemical mechanism leading to the formation of NSS-SO ${ }_{4}^{2-}$ aerosol particles and other sulfur-containing reaction products, such as methanesulfonic acid $\left(\mathrm{CH}_{3} \mathrm{SO}_{3} \mathrm{H}, \mathrm{MSA}\right)$ [Hynes et al., 1986; Yin et al., 1986]. Hynes et al. [1986] suggested that temperature determines the relative contributions of the $\mathrm{OH}$-addition and $\mathrm{H}$-abstraction pathways of the initial oxidation step of DMS

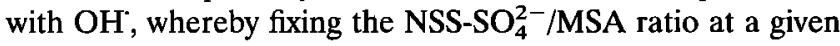
temperature. Kinetic studies on the oxidation of DMS have been critically reviewed [Berresheim et al., 1995; Turnipseed and Ravishankara, 1993; Yin et al., 1990]. A series of recent laboratory [Barone et al., 1995, 1996; Berresheim et al., 1995; Koga and Tanaka, 1996; Sørensen et al., 1996; Tumipseed et al., 1996] and modeling studies [Ayers et al., 1996; Barone et al., 1995; Kerminen et al., 1998a] on the kinetics of the DMS reaction with $\mathrm{OH}^{\circ}$ and $\mathrm{NO}_{3}^{\circ}$ indicate that the $\mathrm{NSS}^{-S_{4}^{2-}} / \mathrm{MSA}$ ratio observed in natural environments is the result of a complex array of reactions involving numerous radical and nonradical intermediates. The ratio is also influenced by any factor influencing $\mathrm{SO}_{2}$ to sulfate conversion in clouds, such as the size distribution of particles, the abundance of sea-salt and anthropogenic particles, and $\mathrm{SO}_{2}$ entrainment from the free troposphere [Kerminen et al., 1998a]. Furthermore, $\mathrm{NO}_{x}(\mathrm{NO}+$ $\mathrm{NO}_{2}$ ) concentrations have been found to influence the yields of MSA, $\mathrm{DMSO}_{2}$ (dimethyl sulfone, $\mathrm{CH}_{3} \mathrm{SO}_{2} \mathrm{CH}_{3}$ ), DMSO (dimethyl sulfoxide, $\mathrm{CH}_{3} \mathrm{SOCH}_{3}$ ), and $\mathrm{SO}_{2}$ [Patroescu et al., 1999], thus further complexifying the $\mathrm{NSS}_{-} \mathrm{SO}_{4}^{2-} / \mathrm{MSA}$ ratio.

Nevertheless, a multitude of field studies reveal that the NSS-SO ${ }_{4}^{2-}$ formation from DMS oxidation is more efficient at higher temperatures than the formation of MSA [Bates et al., 1992; Berresheim et al., 1989, 1991; Bürgermeister and Georgii, 1991; Prospero et al., 1991; Pszenny et al., 1989; Saltzman et al., 1985, 1983; Savoie and Prospero, 1989, 1994; Savoie et al., 1992, 1989]. Reported values for the NSS-SO ${ }_{4}^{2-} / \mathrm{MSA}$ weight ratio vary from 870 , observed over the China Sea [Gao et al., 1996] to 3, observed in Antarctica [Berresheim et al., 1989; Pszenny et al., 1989]. Typical ratios for mid to low latitudes are between 14 and 20 [Berresheim et al., 1991; Burgermeister and Georgii, 1991; Saltzman et al., 1985, 1983; Savoie and Prospero, 1989, 1994], while they range from 3 to 6 for high-latitude summers [Allen et al., 1997; Berresheim et al., 1989; Bürgermeister and Georgii, 1991; Prospero et al., 1991; Pszenny et al., 1989; Savoie et al., 1992].

Continental $\mathrm{SO}_{4}^{2-}$ sources of anthropogenic and crustal nature have been observed even in the remotest regions of the open ocean [Andreae et al., 1986; Berresheim et al., 1991; Esteve et al., 1997; Hoornaert et al., 1996; Savoie and Prospero, 1989; Savoie et al., 1992, 1987; van Malderen et al., 1996; Zhou and Tazaki, 1996]. Neglecting these additional NSS-SO ${ }_{4}^{2-}$ sources may lead to a bias in the NSS-SO ${ }_{4}^{2-}$ /MSA ratios, especially in locations and seasons with low DMS emissions. In these cases, the resulting weak biogenic signal becomes more susceptible to perturbations by nonmarine sources. In the present study we use weighted multivariate linear regression analysis to extract each component of $\mathrm{SO}_{4}^{2-}$ in order to quantify the truly biogenic contribution.

In addition to gas phase DMS oxidation by known oxidants $\left(\mathrm{OH}^{-}\right.$and $\mathrm{NO}_{3}^{-}$), photochemically produced reactive halogens in the marine boundary layer have recently been proposed as important reaction initiators [Andreae and Crutzen, 1997; Keene et al., 1996; Vogt et al., 1996]. Keene et al. [1996] and Andreae and Crutzen [1997] believe that DMS oxidation by $\mathrm{Cl}$ atoms could provide a significant additional sink that would resolve discrepancies between measured and modeled DMS budget analysis [Chin et al., 1996]. Therefore we also present and discuss the observed chloride $\left(\mathrm{Cl}^{-}\right)$concentrations in light of existing knowledge of atmospheric chloride chemistry in the marine boundary layer. Chloride concentrations observed in the field are typically below expected values deduced from sea-salt ratios. Chloride deficits of up to $90 \%$ have been reported [Graedel and Keene, 1995; Keene et al., 1990]. The largest deficits occur as marine air intersects with more polluted air masses [Sturges and Shaw, 1993]. It was widely assumed that the only significant mechanism by which sea salt is dechlorinated involves acidification of the aerosol by $\mathrm{H}_{2} \mathrm{SO}_{4}$ and $\mathrm{HNO}_{3}$, with subsequent volatilization of $\mathrm{HCl}$ [Duce and Hoffmann, 1976; Duce et al., 1973; Sturges and Barrie, 1988]. However, a large number of studies have found that the extent of dechlorination of the aerosol cannot be explained only by $\mathrm{HCl}$ displacement reactions involving mineral acids [Graedel and Keene, 1995, 1996; Keene et al., 1996, 1990]. Experimental evidence [Finlayson-Pitts, 1983; Finlayson-Pitts et al., 1989; Graedel and Keene, 1995; Keene et al., 1990; Pszenny et al., 1993; Vogt et al., 1996] reveals the existence of highly reactive $\mathrm{Cl}$ gases $\left(\mathrm{Cl}_{2}, \mathrm{HOCl}, \mathrm{ClNO}_{2}, \mathrm{NOCl}, \mathrm{BrCl}\right)$ which photolyze or hydrolyze readily to from reactive $\mathrm{Cl}$. Reactive $\mathrm{Cl}$ can initiate photochemical reactions in an analogous manner to $\mathrm{OH}^{\circ}$ and have major consequences for the oxidation of hydrocarbons and DMS [Keene et al., 1996, 1990; Langer et al., 1996; Pszenny et al., 1993; Sander and Crutzen, 1996; Stickel et al., 1992; Vogt et al., 1996].

\section{Experiment}

\subsection{Sampling Location and Period}

Samples were collected over the Arabian Sea during two separate month-long cruises on the R/V Meteor funded by the German Indian Ocean Joint Global Ocean Flux Study (JGOFS). Meteor 32/3 (M32/3) initiated in Muscat, Oman $\left(58.3^{\circ} \mathrm{E}, 23.8^{\circ} \mathrm{N}\right)$, and ended in Mahe, Seychelles $\left(55.5^{\circ} \mathrm{E}\right.$, $4.5^{\circ} \mathrm{S}$ ), cruising for the whole month of May of 1995 , while Meteor 32/5 (M32/5) backtracked M32/3's path, during the latter half of July and the first half of August of the same year. For most of the time, both the cruises tracked the 65th east meridian. The month of May, during which M32/3 took place, is typically characterized by no predominant weather pattern over the northern Indian Ocean. It is the end of the transition time between the NE (also, winter) and the SW monsoon (also, summer monsoon) and is therefore called the intermonsoon. 
M32/5 took place during the SW monsoon. Daily threedimensional isentropic air mass back trajectory calculations were provided by the German Weather Service and are presented by Siefert et al. [1999, Figure 1].

During the northern part of $M 32 / 3$ (intermonsoon), air masses advected over Africa, the Middle East, and/or Asia, while the southern portion of the same cruise was characterized by slower moving marine air masses coming from the open ocean. Strong SW winds dominated meteorological conditions during the SW monsoon. All air masses originated from the open ocean, and with exception for a few higher elevation air masses in the latter half of the cruise, most of the air masses during the SW monsoon did not have contact with continental land. This pattern of persistent high-speed air current, in the form of a system of low-level jet streams in the vicinity of the western Indian Ocean during the northern summer, named Findlater Jet [Findlater, 1969], also leads to major areas of upwelling in the ocean off of the coast of Somalia, which was observed during the M32/5 cruise.

\subsection{Aerosol Collection}

Ambient aerosol samples were collected with two collector types. One high-volume dichotomous virtual impactor (HVDVI) served for the collection of trace metals in two size fractions, described in detail by Siefert et al. [1999]. Two lowvolume collectors, running at a flow rate of $27 \mathrm{~L} / \mathrm{min}$, were used to collect aerosol samples for anion, cation, and gravimetric analyses, to be presented in this study. For the lowvolume collectors, inverted high-density polyethylene $2 \mathrm{~L}$ bottles served as rainshields for the Nucleopore polycarbonate filter holders which were loaded with acid-cleaned $47 \mathrm{~mm}$ diameter Gelman Zefluor filters ( $1 \mu \mathrm{m}$ pore size).

A sector sampling system controlled the operation of all the pumps, thereby stopping collection of all aerosol collectors simultaneously when wind speed or wind direction were out of sector. The data logger was programmed to shut the pumps off when the wind speed was equal to $0 \mathrm{~m} \mathrm{~s}^{-1}$ and when the relative wind direction was $\pm 90^{\circ}$ off of the bow of the ship during the intermonsoon and $\pm 60^{\circ}$ during the SW monsoon.

In general, samples represent daily averages, but due to the ship's cruise track, actual sampling duration may vary. Exact sampling intervals for each sample are presented by Siefert et al. [1999, Table 1].

\subsection{Chemical Analysis}

Labile ferrous iron was analyzed spectrophotometrically on the high-volume filters immediately after sample collection on board the ship; see Siefert et al. [1999] for details. Filter samples for anion and cation analyses were refrigerated in cleaned petri dishes until they were analyzed after the research cruise.

Elemental analysis of 31 elements $(\mathrm{Na}, \mathrm{Mg}, \mathrm{Al}, \mathrm{K}, \mathrm{Ca}, \mathrm{Sc}, \mathrm{Ti}$, $\mathrm{V}, \mathrm{Cr}, \mathrm{Mn}, \mathrm{Fe}, \mathrm{Ni}, \mathrm{Cu}, \mathrm{Zn}, \mathrm{Ge}, \mathrm{As}, \mathrm{Se}, \mathrm{Mo}, \mathrm{Ru}, \mathrm{Cd}, \mathrm{Sn}, \mathrm{Sb}, \mathrm{Cs}$, $\mathrm{Ba}, \mathrm{La}, \mathrm{Ce}, \mathrm{Sm}, \mathrm{Eu}, \mathrm{Hf}, \mathrm{Pb}$, and $\mathrm{Th}$ ) was performed on the high-volume filters with an Inductively Coupled Mass Spectrometer (ICP-MS). Methods and results of this analysis are presented by Siefert et al. [1999], but some of the metal abundance data will be used here.

For the ion analyses the $47 \mathrm{~mm}$ diameter low-volume filters were first wetted with approximately $0.2 \mathrm{~mL}$ ethanol then extracted overnight in $10 \mathrm{~mL}$ MQ water. Anions were separated and quantified with a Dionex Bio LC ion chromatograph using a OmniPac Pax-500 separator column and the corresponding guard column. A AMMS-II anion micromembrane suppressor ensured the lowest possible background noise levels and detection limits. Organic and inorganic anions were eluted with a gradient pump and a combination of 3 eluents $(1 \mathrm{~m} M \mathrm{NaOH}$, $200 \mathrm{~m} M \mathrm{NaOH}, 5 \% \mathrm{MeOH}$ ), whereby the $\mathrm{NaOH}$ concentration was ramped from an initial $0.75 \mathrm{~m} M$ to a final $80.35 \mathrm{~m} M$, while the $\mathrm{MeOH}$ component remained constant at $1.24 \%$. All anions eluted within 30 min of running time, but 9 additional min were required to reequilibrate the column to the same initial conditions after every run. Inorganic anions detected for were fluoride, chloride, nitrite, bromide, nitrate, and sulfate, while the organic anions were acetate, glycolate, formate, methanesulfonate, malonate, and oxalate. Propionate, pyruvate, succinate, fumarate, phthalate, phosphate, and citrate were only present at nondetectable concentrations.

Cations were separated and quantified isocratically on the same Bio LC chromatograph with IonPac CS10 analytical and guard columns and a $40 \mathrm{~m} M \mathrm{HCl}$ eluent. Sodium, ammonium, potassium, magnesium, and calcium concentrations were determined. Daily average total suspended particulate (TSP) mass was determined by difference in filter weights (equilibrated to $21^{\circ} \mathrm{C}$ and $50 \%$ relative humidity $(\mathrm{RH})$ ) before and after collection.

\subsection{Statistical Analysis}

All concentrations are accompanied by their standard deviation calculated through propagation of error in every parameter used. The estimated errors in the volume of air sampled, in the filter section cut, in the volume of the extraction solution, etc., were assumed at $10 \%$. The detection limits were determined as the mean of the blanks plus 3 times the standard deviation.

Principal component analysis by Statistical Product and Service Solutions (SPSS) [1997] was performed on the whole data set, including the metals, to learn about the source characteristics that made up the sampled aerosol material. In a principal component analysis the correlation matrix of the observed variables is examined to reduce the number of descriptive variables by linearly combining the observed ones into a smaller set of independent variables, the principal components. The principal components are orthogonal to each other and can be rotated in space to simplify interpretation of the data set. A common type of rotation is the Varimax rotation, during which orthogonality is retained. All principal components in the present study are Varimax-rotated.

A principal component in this study represents a source, such as crustal material, sea salt, anthropogenic pollutants, etc. An observed variable will display a number close to 1 if it correlates with the principal component, thus two variables with numbers close to 1 in one component correlate with each other. For example, the crustal component will exhibit values close to 1 for $\mathrm{Al}$ and other crustal elements, while the sea-salt component will exhibit values close to 1 for variables that are characteristic for sea salt, such as $\mathrm{Na}^{+}, \mathrm{Cl}^{-}$, and wind speed.

\section{Results and Discussion}

\section{1. $\mathrm{SO}_{4}^{2-}$ and MSA}

3.1.1. Atmospheric concentrations. Particulate $\mathrm{SO}_{4}^{2-}$ and MSA are determined as described in the experimental section above. $\mathrm{NSS}_{-} \mathrm{SO}_{4}^{2-}$ is estimated by subtracting sea-salt $\mathrm{SO}_{4}^{2-}$ from the total $\mathrm{SO}_{4}^{2-}$, where the sea-salt component is inferred from $\mathrm{Na}^{+}$concentrations and the constant $\mathrm{SO}_{4}^{2-} / \mathrm{Na}^{+}$ocean water ratio (0.252 [from Millero and Sohn, 1992]). Total and 
NSS-SO ${ }_{4}^{2-}$ are plotted in Figure 1a. The format of this plot is analogous to the rest of the concentration-versus-sample plots in this study; samples are plotted as a function of time, intermonsoon samples to the left, and SW monsoon samples to the right of the vertical line that represents the equator. Thus the abscissa is a temporal as well as a spatial variable, where each sample, in general, represents 1 day.

The $\mathrm{SO}_{4}^{2-}$ data show stronger anthropogenic sulfate inputs during the intermonsoon, especially early in the cruise when closer to continental landmasses, as compared to the SW monsoon. Strong winds during the SW monsoon produced high loadings of sea-salt aerosol; therefore a larger sea-salt component to total $\mathrm{SO}_{4}^{2-}$ is observed during that season. Table 1 lists the average, maximum, and minimum concentrations of all anions and cations during both seasons. Sodium, a tracer for sea salt, is larger by a factor of 2.5 during the SW monsoon compared to the intermonsoon.

Figure 1b shows the particulate MSA concentrations. Concentrations decrease over the oligotrophic waters located near the equator and during the SW monsoon, while the MSA concentrations reach a maximum in the coastal upwelling regions off the coast of Oman due to increased biologic activity (samples M32/5_13, 14, and 15). This elevated biologic productivity was also recorded by Bange et al. [1996] based on increased $\mathrm{N}_{2} \mathrm{O}(\mathrm{g})$ emissions from the ocean.

3.1.2. $\mathrm{Bio}-\mathrm{SO}_{4}^{2-} / \mathrm{MSA}$ ratio. $\mathrm{NSS}_{-} \mathrm{SO}_{4}^{2-}$ can be composed of a series of components. It is only in the rare case when no other than biogenic sources are present that all NSS-SO ${ }_{4}^{2-}$ is derived from the oxidation of biogenically emitted $\mathrm{S}$ gases. Linear regression analyses, described in the next section, and the large $\mathrm{Ca}^{2+}$ concentrations reveal the presence of gypsum as a $\mathrm{SO}_{4}^{2-}$ source in the intermonsoon samples. Thus, to prevent all ambiguity, the following definitions are introduced here:

$$
\begin{gathered}
\text { total- } \mathrm{SO}_{4}^{2-}=\mathrm{SO}_{4}^{2-}=\mathrm{SS}_{-} \mathrm{SO}_{4}^{2-}+\text { bio- } \mathrm{SO}_{4}^{2-} \\
+ \text { anthr- } \mathrm{SO}_{4}^{2-}+\text { gyp-SO}
\end{gathered}
$$

therefore

$$
\begin{gathered}
\mathrm{NSS}-\mathrm{SO}_{4}^{2-}=\mathrm{SO}_{4}^{2-}-\mathrm{SS}-\mathrm{SO}_{4}^{2-}=\text { bio- } \mathrm{SO}_{4}^{2-} \\
+ \text { anthr- } \mathrm{SO}_{4}^{2-}+\text { gyp-SO } \\
+\mathrm{SO}_{4}^{2-},
\end{gathered}
$$

where $\mathrm{SS}_{-} \mathrm{SO}_{4}^{2-}$, bio- $\mathrm{SO}_{4}^{2-}$, anthr- $\mathrm{SO}_{4}^{2-}$, and gyp- $\mathrm{SO}_{4}^{2-}$ represent the sea-salt, biogenic, anthropogenic, and gypsum contributions, respectively. Of special interest is the biogenic contribution, bio- $\mathrm{SO}_{4}^{2-}$, and not the NSS-SO${ }_{4}^{2-}$.

A strong anthropogenic $\mathrm{SO}_{4}^{2-}$ component during the intermonsoon contributes to a relatively high value for NSS-SO ${ }_{4}^{2-}$. The resulting inflated NSS-SO ${ }_{4}^{2-} / \mathrm{MSA}$ ratio would misrepresent the biogenic contribution if the anthropogenic fraction were neglected and not properly determined. In Figure 1c, NSS-SO ${ }_{4}^{2-}$ concentrations are plotted against observed MSA concentrations. The slope of the least squares fit through the intermonsoon data set reveals a large NSS-SO ${ }_{4}^{2-} / \mathrm{MSA}$ weight ratio $(60 \pm 10)$ in close agreement with other studies performed in areas impacted heavily by continental sulfur emissions [Allen et al., 1997; Berresheim et al., 1991; Saltzman et al., 1983; Savoie et al., 1989]. A more reasonable value during the SW monsoon $(14 \pm 3)$ is consistent with other observations from comparable parts of the remote open ocean [Bürgermeister and Georgii, 1991; Gao et al., 1996; Saltzman et al., 1985, 1983; Savoie and Prospero, 1989, 1994]. The three samples collected near the Omani coast, which displayed larger than average MSA concentrations, are plotted but excluded from the linear regression and will be considered separately.

Note that low concentration samples from the intermonsoon in the left bottom corner of the plot fall on a line with the SW monsoon samples. Back trajectories of these samples indicate no recent contact with continental landmasses and can therefore be considered "clean" of anthropogenic and crustal material. Thus it is justified to believe that the NSS-SO ${ }_{4}^{2-}$ MSA weight ratio of $\sim 14$ in the present case is a good estimate of the biogenically derived sulfur in this region. Nevertheless, following is a methodical statistical procedure that deconvolutes the observed total- $\mathrm{SO}_{4}^{2-}$ to reveal all its sources and their relative contributions, and to unveil the truly biogenic fraction, especially for the "dirty" intermonsoon samples.

3.1.3. Linear regression: General. Several weighted multiple linear regression analyses are performed on each data set (intermonsoon, SW monsoon, and the three SW monsoon "outliers") where $\mathrm{SO}_{4}^{2-}$ is the dependent variable and the independent variables are other carefully selected atmospheric species. Each conceivable source of $\mathrm{SO}_{4}^{2-}$ is represented by a tracer, that is, an independent variable, where the coefficient by which the tracer is multiplied is a measure of the extent to which $\mathrm{SO}_{4}^{2-}$ is related to that given variable after removing the effect of all the other variables. The coefficients are called partial regression coefficients and denoted $b_{t}$ in the regression analysis. The standardized regression coefficients $\left(\beta_{i}=b_{z}\left(s_{x} /\right.\right.$ $\left.s_{y}\right)$ ) can be directly compared with each other and are used as indicators of relative importance of the various sources in determining the value of $\mathrm{SO}_{4}^{2-}$.

There are several objective ways of testing the significance of a regression and the significance of each chosen variable. From the analysis of variance (ANOVA) output of the linear regression, $F$, the ratio of the regression and residual mean squares, is a measure of the strength of the relationship in the data (for a more detailed description, refer to Zar [1996]). If $F$ for the regression is significant, then each of the partial regression coefficients in a multiple regression equation may be submitted to an analogous test. Here the student $t$-test is performed on the partial regression coefficients. However, in general, a significant $F$ value in testing the dependence of $Y$ (here $\mathrm{SO}_{4}^{2-}$ ) on all $X$ values will be associated with significance of some of the $b$ values being concluded by the $t$-test; but it is possible to have a significant $F$ without any significant $t$ values, or even significant $t$ values without significant $F$. The latter situations often indicate a high degree of correlation between the several independent variables.

In the present study, multiple models are run with different numbers and combinations of variables due to the availability of a large set of variables (anions, cations, and metals [Siefert et al., 1999]). By examination of the residual mean squares $\left(R^{2}\right)$, the $F$ and $t$ values, as described above, those regressions and variables with the optimal conditions were retained. A few of the models for each data set are discussed in an attempt to show the objectiveness of the final choice of model.

3.1.4. Linear regression: Intermonsoon (M32/3). Table 2 displays the ANOVA output, coefficients, and additional statistical information for four linear regressions for the 27 intermonsoon samples. $\mathrm{Na}^{+}$was included as the sea-salt tracer and served as an additional test of the model since the exact ratio is known (0.252 [from Millero and Sohn, 1992]) and thus expected to coincide with the partial regression coefficient for $\mathrm{Na}^{+}$in the analysis. MSA represents the biogenic $\mathrm{SO}_{4}^{2-}$ con- 

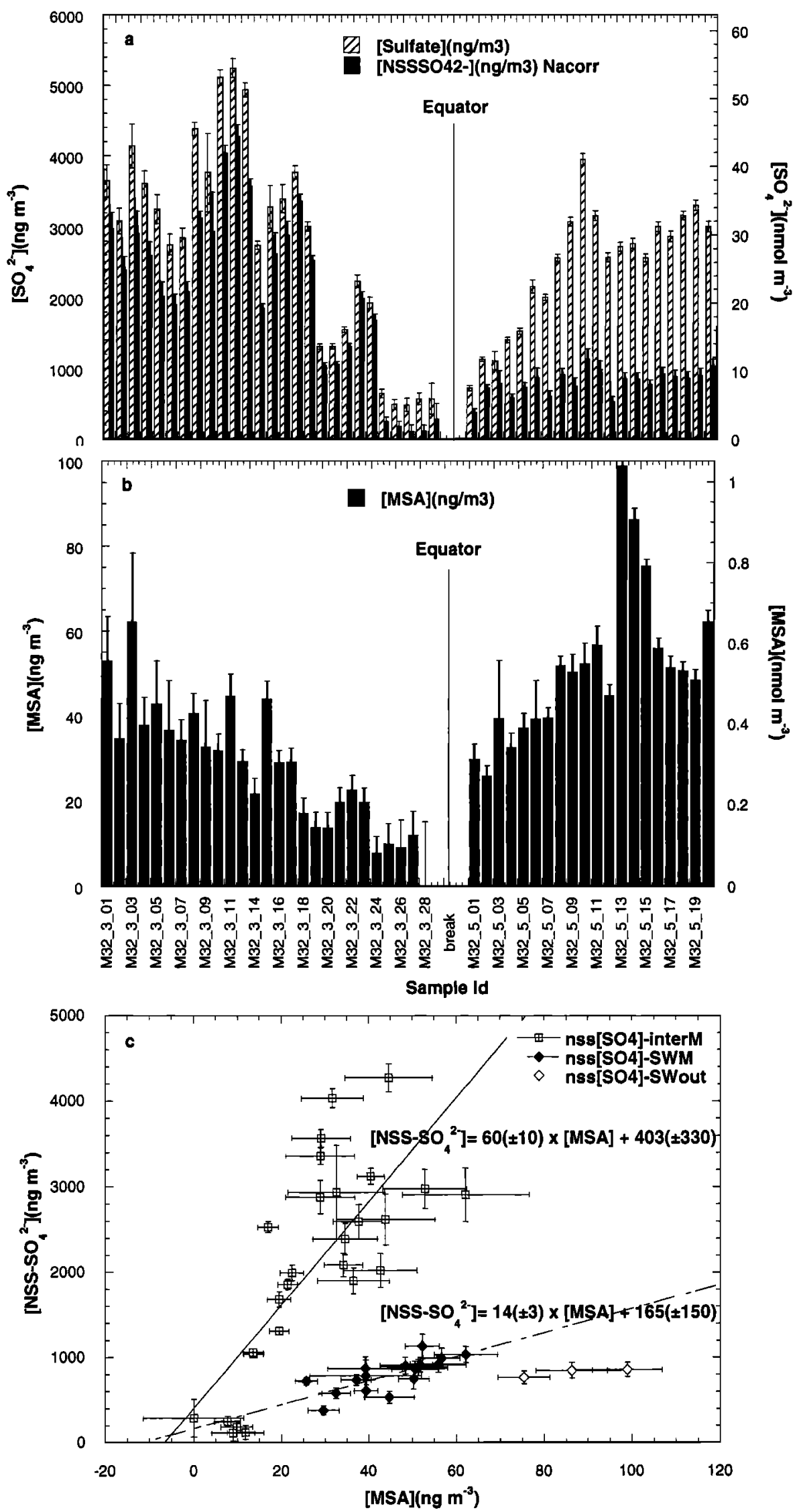

Figure 1. Sulfur species during intermonsoon and SW monsoon: (a) $\mathrm{SO}_{4}^{2-}, \mathrm{NSS}_{-} \mathrm{SO}_{4}^{2-}$ and (b) MSA versus sample; (c) NSS-SO ${ }_{4}^{2-}$ versus MSA. 
Table 1. Atmospheric Anion and Cation Concentrations During Intermonsoon and SW Monsoon

\begin{tabular}{|c|c|c|c|c|c|c|c|c|}
\hline \multirow[b]{2}{*}{ Species } & \multicolumn{4}{|c|}{ Intermonsoon } & \multicolumn{4}{|c|}{ SW Monsoon } \\
\hline & $\begin{array}{l}\text { Average Plus } \\
\text { or Minus s.d. }\end{array}$ & Minimum & Maximum & $\begin{array}{c}\text { Number of } \\
\text { Samples }\end{array}$ & $\begin{array}{l}\text { Average Plus } \\
\text { or Minus s.d. }\end{array}$ & Minimum & Maximum & $\begin{array}{c}\text { Number of } \\
\text { Samples }\end{array}$ \\
\hline $\mathbf{F}^{-}$ & $5.1 \pm 2.8$ & 1.5 & 10.3 & 28 & $2.1 \pm 1.3$ & 0.7 & 5.6 & 20 \\
\hline $\mathrm{Cl}^{-}, \mu \mathrm{g} \mathrm{m}^{-3}$ & $4.1 \pm 2.3$ & 1.2 & 7.9 & 28 & $11.1 \pm 4.8$ & 2.5 & 18.3 & 20 \\
\hline $\mathrm{NO}_{2}^{-}$ & $7.2 \pm 8.7$ & BDL & 28.7 & 28 & $18.6 \pm 1.7$ & BDL & 51.5 & 20 \\
\hline $\mathrm{Br}^{-2}$ & $0.5 \pm 0.2$ & BDL & 6.8 & 28 & $12.7 \pm 13.9$ & BDL & 34.1 & 20 \\
\hline $\mathrm{NO}_{3}^{-}, \mu \mathrm{g} \mathrm{m}^{-3}$ & $1.23 \pm 0.41$ & 0.60 & 2.18 & 28 & $0.46 \pm 0.12$ & 0.23 & 0.64 & 20 \\
\hline $\mathrm{SO}_{4}^{2-}, \mu \mathrm{g} \mathrm{m}^{-3}$ & $2.74 \pm 1.47$ & 0.49 & 5.24 & 28 & $2.44 \pm 0.86$ & 0.72 & 3.94 & 20 \\
\hline NSS-SO ${ }_{4}^{2-}, \mu \mathrm{g} \mathrm{m}^{-3}$ & $2.08 \pm 1.21$ & 0.11 & 4.27 & 28 & $0.80 \pm 0.18$ & 0.38 & 1.13 & 20 \\
\hline Acetate & $86.0 \pm 174.8$ & $\mathrm{BDL}$ & 734.6 & 28 & $19.5 \pm 10.7$ & 4.9 & 51.7 & 20 \\
\hline Glycolate & $3.4 \pm 4.1$ & BDL & 13.0 & 28 & $8.7 \pm 4.6$ & 2.8 & 16.2 & 20 \\
\hline Formate & $20.4 \pm 19.0$ & 4.6 & 73.6 & 28 & $21.1 \pm 13.8$ & 4.9 & 46.3 & 20 \\
\hline MSA & $27.0 \pm 15.3$ & BDL & 62.1 & 28 & $51.3 \pm 18.4$ & 25.6 & 98.9 & 20 \\
\hline Malonate & $56.1 \pm 96.4$ & $\mathrm{BDL}$ & 278.4 & 28 & $31.9 \pm 32.1$ & $\mathrm{BDL}$ & 84.7 & 20 \\
\hline Oxalate & $88.5 \pm 43.7$ & 14.7 & 175.1 & 28 & $69.3 \pm 35.8$ & 18.2 & 179.2 & 20 \\
\hline $\mathrm{Na}^{+}, \mu \mathrm{g} \mathrm{m}^{-3}$ & $2.6 \pm 1.4$ & 0.9 & 5.4 & 28 & $6.5 \pm 2.9$ & 1.3 & 11.2 & 20 \\
\hline $\mathrm{NH}_{4}^{+}$ & $290.5 \pm 194.9$ & 45.4 & 774.2 & 28 & $46.4 \pm 31.5$ & 21.6 & 154.6 & 20 \\
\hline $\mathrm{K}^{+4}$ & $175.7 \pm 105.2$ & 54.2 & 415.1 & 28 & $271.8 \pm 144.5$ & $\mathrm{BDL}$ & 571.3 & 20 \\
\hline $\mathrm{Mg}^{2+}, \mu \mathrm{g} \mathrm{m}^{-3}$ & $0.31 \pm 0.17$ & 0.09 & 0.66 & 28 & $0.66 \pm 0.30$ & 0.10 & 1.09 & 20 \\
\hline $\mathrm{Ca}^{2-}, \mu \mathrm{g} \mathrm{m}^{-3}$ & $1.06 \pm 0.91$ & 0.01 & 2.94 & 28 & $0.41 \pm 0.25$ & 0.03 & 0.87 & 20 \\
\hline
\end{tabular}

Average (plus or minus standard deviation), minimum, and maximum concentrations (in $\mathrm{ng} \mathrm{m}^{-3}$ unless otherwise indicated), and number of samples. BDL, below detection limit.

tribution. The existence of an anthropogenic component is known, but the tracer needs a careful selection due to its crucial effect on the outcome of the model. Comparison of models 3 and 4 in Table 2, where the input differences are the choice of the anthropogenic tracer, $\mathrm{Pb}$ and $\mathrm{NO}_{3}^{-}$, respectively, shows that model 3 is the better regression model and that $\mathrm{Pb}$ is the better variable (Vanadium, not shown, did not qualify) according to the $t$-test and ANOVA output. In addition, the standardized coefficients $\left(0.108\right.$ for $\mathrm{NO}_{3}^{-}$as opposed to 0.482 for $\mathrm{Pb}$ ) indicate the stronger dependence of $\mathrm{Pb}$ on $\mathrm{SO}_{4}^{2-}$. The relative difference in the resulting bio- $\mathrm{SO}_{4}^{2-} / \mathrm{MSA}$ weight ratio between the two models ( 35.7 in model 4 , as opposed to 17.7 in model 3) shows how misleading the results would have been, if $\mathrm{NO}_{3}^{-}$were chosen as the anthropogenic tracer.

The plots shown in Figure 2 confirm the choice of $\mathrm{Pb}$ over $\mathrm{NO}_{3}^{-}$as the optimal anthropogenic tracer for the intermonsoon samples; the correlation between $\mathrm{Pb}$ and $\mathrm{NSS}_{-} \mathrm{SO}_{4}^{2-}$, as depicted in Figure 2a, is considerably higher than between $\mathrm{NO}_{3}^{-}$and NSS-SO${ }_{4}^{2-}$, shown in Figure $2 \mathrm{~b}$.

An additional $\mathrm{SO}_{4}^{2-}$ source was detected during the intermonsoon in association with enriched soluble $\mathrm{Ca}$. Calcium as detected by the IC $\left(\mathrm{Ca}^{2+}\right)$ for these samples was found on

Table 2. M32/3 Intermonsoon: Model Outputs From Weighted Linear Least Squares Regressions With $\mathrm{SO}_{4}^{2-} \mathrm{Being}$ the Dependent Variable in All Cases

\begin{tabular}{|c|c|c|c|c|c|c|c|c|c|c|c|}
\hline \multirow[b]{2}{*}{ Model } & \multicolumn{3}{|c|}{$\begin{array}{c}\text { Model Summary Analysis of } \\
\text { Variance }\end{array}$} & \multirow[b]{2}{*}{$\begin{array}{l}\text { Independent } \\
\text { Variables }\end{array}$} & \multirow{2}{*}{$\begin{array}{c}\text { Unstandardized } \\
\text { Coefficients } \\
b{ }_{r}\end{array}$} & \multirow[b]{2}{*}{$\begin{array}{l}\text { Standard } \\
\text { Error }\end{array}$} & \multirow{2}{*}{$\begin{array}{c}\text { Standardızed } \\
\text { Coefficients } \\
\beta_{\imath}\end{array}$} & \multirow[b]{2}{*}{$t$} & \multirow[b]{2}{*}{ Significance } & \multicolumn{2}{|c|}{$\begin{array}{l}\text { Ninety-five Percent } \\
\text { Confidence Interval } \\
\text { for } b\end{array}$} \\
\hline & $R^{2}$ & $F$ & Significance & & & & & & & $\begin{array}{l}\text { Lower } \\
\text { Bound }\end{array}$ & $\begin{array}{l}\text { Upper } \\
\text { Bound }\end{array}$ \\
\hline \multirow[t]{6}{*}{1} & 0.971 & 141.654 & 0.000 & (constant) & 26.859 & 128.870 & & 0.201 & 0.843 & -251.567 & 305.850 \\
\hline & & & & MSA & 17.489 & 133.884 & 0.222 & 3.444 & 0.002 & 6.929 & 28.048 \\
\hline & & & & $\mathrm{Na}^{+}$ & 0.251 & 0.056 & 0.254 & 4.501 & 0.000 & 0.135 & 0.367 \\
\hline & & & & Al & -0.086 & 0.437 & -0.230 & -0.197 & 0.846 & -0.994 & 0.822 \\
\hline & & & & $\mathbf{P b}$ & 773.499 & 123.788 & 0.541 & 6.249 & 0.000 & 516.069 & 1030.930 \\
\hline & & & & NSS-Ca ${ }^{2+}$ & 0.334 & 0.158 & 0.218 & 2.110 & 0.047 & 0.005 & 0.663 \\
\hline \multirow[t]{5}{*}{2} & 0.971 & 185.147 & 0.000 & (constant) & 20.443 & 126.996 & & 0.161 & 0.874 & -242.931 & 283.817 \\
\hline & & & & MSA & 17.613 & 4.927 & 0.224 & 3.575 & 0.002 & 7.396 & 27.830 \\
\hline & & & & $\mathrm{Na}^{+}$ & 0.253 & 0.053 & 0.256 & 4.734 & 0.000 & 0.142 & 0.364 \\
\hline & & & & $\mathrm{Pb}$ & 761.153 & 104.407 & 0.532 & 7.290 & 0.000 & 544.626 & 977.681 \\
\hline & & & & NSS-Ca ${ }^{2+}$ & 0.309 & 0.090 & 0.201 & 3.424 & 0.002 & 0.122 & 0.495 \\
\hline \multirow[t]{4}{*}{3} & 0.996 & 1395.823 & 0.000 & MSA & 17.699 & 4.793 & 0.190 & 3.693 & 0.001 & 7.783 & 27.614 \\
\hline & & & & $\mathrm{Na}^{+}$ & 0.256 & 0.049 & 0.248 & 5.243 & 0.000 & 0.155 & 0.357 \\
\hline & & & & $\mathbf{P b}$ & 763.381 & 101.271 & 0.482 & 7.538 & 0.000 & 553.885 & 972.877 \\
\hline & & & & NSS-Ca ${ }^{2+}$ & 0.310 & 0.088 & 0.118 & 3.535 & 0.002 & 0.129 & 0.491 \\
\hline \multirow[t]{4}{*}{4} & 0.987 & 434.410 & 0.000 & MSA & 35.719 & 7.251 & 0.383 & 4.926 & 0.000 & 20.720 & 50.719 \\
\hline & & & & $\mathrm{Na}^{+}$ & 0.319 & 0.087 & 0.309 & 3.678 & 0.001 & 0.140 & 0.499 \\
\hline & & & & $\mathrm{NO}_{3}^{-}$ & 0.280 & 0.195 & 0.108 & 1.438 & 0.164 & -0.123 & 0.683 \\
\hline & & & & NSS-Ca ${ }^{2+}$ & 0.693 & 0.139 & 0.264 & 4.997 & 0.000 & 0.406 & 0.980 \\
\hline
\end{tabular}

Concentrations in units $\mathrm{ng}^{-3} ; 27$ data points. 

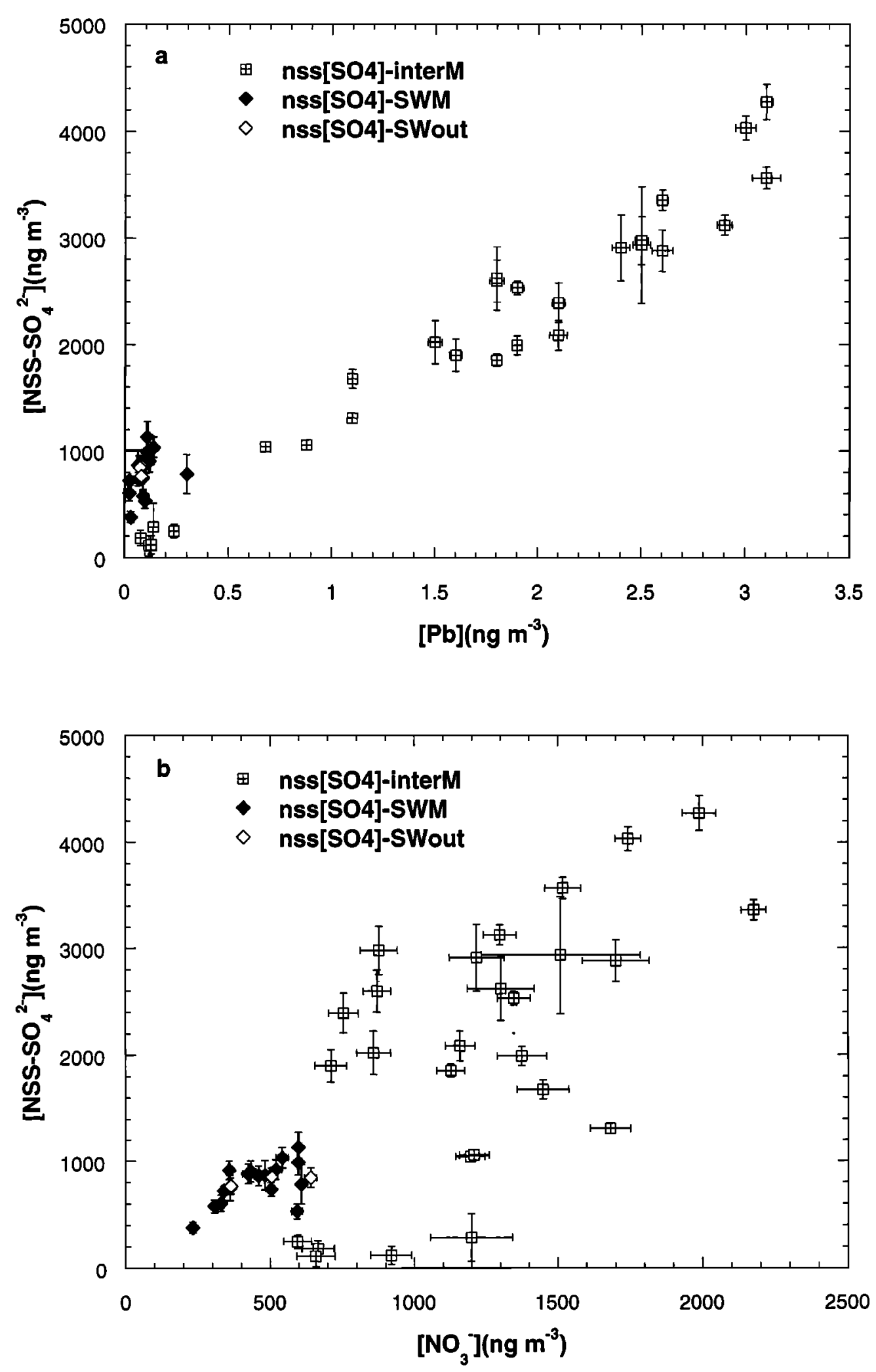

Figure 2. NSS-SO $\mathrm{SO}_{4}^{2-}$ versus (a) $\mathrm{Pb}$ and versus (b) $\mathrm{NO}_{3}^{-}$during intermonsoon and $\mathrm{SW}$ monsoons.

average to be enriched 12 times over concentrations expected from the sea-salt tracer $\mathrm{Na}^{+}$. ICP-MS analysis revealed varying crustal enrichments of NSS-Ca of up to a factor of 5 over the crustal tracer Al. These crustal enrichment calculations are based on several assumptions that are explained in more detail below. In Plate 1d the IC and ICP-MS Ca data for each sample are presented, whereby the stacked bars add up to measured total ICP-MS Ca concentrations. Note the large 
Table 3. M32/5 SW Monsoon: Model Outputs From Weighted Linear Least Squares Regressions With $\mathrm{SO}_{4}^{2-}$ Being the Dependent Variable in All Cases

\begin{tabular}{|c|c|c|c|c|c|c|c|c|c|c|c|}
\hline \multirow[b]{2}{*}{ Model } & \multicolumn{3}{|c|}{$\begin{array}{c}\text { Model Summary Analysis of } \\
\text { Variance }\end{array}$} & \multirow[b]{2}{*}{$\begin{array}{l}\text { Independent } \\
\text { Variables }\end{array}$} & \multirow{2}{*}{$\begin{array}{c}\text { Unstandardized } \\
\text { Coefficients } \\
b_{2}\end{array}$} & \multirow[b]{2}{*}{$\begin{array}{l}\text { Standard } \\
\text { Error }\end{array}$} & \multirow{2}{*}{$\begin{array}{c}\text { Standardized } \\
\text { Coefficients } \\
\beta_{\imath}\end{array}$} & \multirow[b]{2}{*}{$t$} & \multirow[b]{2}{*}{ Significance } & \multicolumn{2}{|c|}{$\begin{array}{c}\text { Ninety-Five Percent } \\
\text { Confidence Interval } \\
\text { for } b\end{array}$} \\
\hline & $R^{2}$ & $F$ & Significance & & & & & & & $\begin{array}{l}\text { Lower } \\
\text { Bound }\end{array}$ & $\begin{array}{l}\text { Upper } \\
\text { Bound }\end{array}$ \\
\hline \multirow[t]{6}{*}{1} & 0.990 & 218.041 & 0.000 & (constant) & 264.514 & 165.401 & & 1.599 & 0.138 & -99.530 & 628.558 \\
\hline & & & & MSA & 3.848 & 6.120 & 0.039 & 0.629 & 0.542 & -9.622 & 17.317 \\
\hline & & & & $\mathrm{Na}^{+}$ & 0.307 & 0.025 & 1.070 & 12.489 & 0.000 & 0.252 & 0.361 \\
\hline & & & & $\mathrm{Al}$ & 1.119 & 1.432 & 0.044 & 0.781 & 0.451 & -2.033 & 4.271 \\
\hline & & & & $\mathrm{Pb}$ & 841.968 & 613.618 & 0.070 & 1.372 & 0.197 & -508.596 & 2192.531 \\
\hline & & & & NSS-Ca ${ }^{2+}$ & -0.882 & 0.326 & -0.155 & -2.709 & 0.020 & -1.599 & -0.165 \\
\hline \multirow[t]{5}{*}{2} & 0.983 & 129.105 & 0.000 & (constant) & 2.253 & 310.946 & & 0.007 & 0.994 & -701.155 & 705.661 \\
\hline & & & & MSA & 13.832 & 8.629 & 0.137 & 1.603 & 0.143 & -5.689 & 33.353 \\
\hline & & & & $\mathrm{Na}^{+}$ & 0.248 & 0.029 & 0.863 & 8.549 & 0.000 & 0.182 & 0.313 \\
\hline & & & & $\mathrm{Pb}$ & -201.701 & 938.192 & -0.017 & -0.215 & 0.835 & -2324.037 & 1920.636 \\
\hline & & & & $\mathrm{NO}_{3}^{-}$ & 0.502 & 0.532 & 0.062 & 0.943 & 0.370 & -0.701 & 1.704 \\
\hline \multirow[t]{3}{*}{3} & 0.998 & 1520.912 & 0.000 & MSA & 13.495 & 4.407 & 0.245 & 3.062 & 0.011 & 3.795 & 23.195 \\
\hline & & & & $\mathrm{Na}^{+}$ & 0.251 & 0.016 & 0.687 & 15.641 & 0.000 & 0.216 & 0.287 \\
\hline & & & & $\mathrm{NO}_{3}^{-}$ & 0.443 & 0.299 & 0.086 & 1.484 & 0.166 & -0.214 & 1.101 \\
\hline
\end{tabular}

Concentrations in units $\mathrm{ng}^{-3} ; 17$ data points.

non-sea-salt, noncrustal fraction for $\mathrm{Ca}$ (in green) during the intermonsoon.

Gypsum $\left(\mathrm{CaSO}_{4}\right)$ has been found in aerosols associated with crustal material [Andreae et al., 1986; Esteve et al., 1997; Hoomaert et al., 1996; Zhou and Tazaki, 1996] and in aerosols collected over the Indian Ocean by Savoie et al. [1987]. Therefore NSS-Ca ${ }^{2+}$ (corrected for the sea-salt-Ca ${ }^{2+}$ estimated from soluble $\mathrm{Na}^{+}$) was included in the linear regression analysis to portray this crustal- $\mathrm{SO}_{4}^{2-}$ contribution, denoted gyp$\mathrm{SO}_{4}^{2-}$.

Model 1, which is presented in Table 2, includes all the above mentioned tracers, $\mathrm{Na}^{+}, \mathrm{MSA}, \mathrm{Pb}$, and $\mathrm{NSS}-\mathrm{Ca}^{2+}$, in addition to Al. Aluminum is added to check if the gypsum component is associated with the crustal component, thus indicating a common source. The $t$-test for $\mathrm{Al}$ in model 1 shows a conditional probability, that a relationship as strong as the one observed in the data would be present if the null hypothesis were true, of $85 \%$. This implies that $\mathrm{Al}$ can be taken out of the model, but it does not exclude the possibility of intercorrelation between the two variables of interest. Thus, when taking out one of the variables at a time, we observe that both $\mathrm{Al}$ (not shown) and NSS-Ca ${ }^{2+}$ are pertinent parameters for the crustal contribution of $\mathrm{SO}_{4}^{2-}$. The statistical output reveals that the better regression includes NSS-Ca ${ }^{2+}$, however, as shown in models 2 and 3 . We conclude that gypsum and the other crustal component, traced by $\mathrm{Al}$, most likcly have a common source. Furthermore, a possible explanation for the better fit obtained with NSS-Ca ${ }^{2+}$ is that it was derived from IC analyses and the low-volume samples, as were $\mathrm{SO}_{4}^{2}, \mathrm{Na}^{r}$, and MSA, while $\mathrm{Al}$ was determined with ICP-MS and from the high-volume filters. However, a differential effect of collection and analysis methods on concentrations does not apply for the preference of $\mathrm{Pb}$ as anthropogenic tracer over $\mathrm{NO}_{3}^{-}$. Thus, most likely, more than one factor determines the concentration of gypsum in the aerosol particles. This is further discussed in the next section.

In addition, the constant can be eliminated from model 2 since it is negligible. With these considerations, model 3 appears to be the best representation of the intermonsoon data set. Model 3 provides a sea-salt coefficient that is close to the expected 0.252 for ocean water, and a bio- $\mathrm{SO}_{4}^{2-} / \mathrm{MSA}$ weight ratio of $17.7 \pm 4.8$ for the biogenic $\mathrm{SO}_{4}^{2-}$ contribution during the intermonsoon of 1995.

3.1.5. Linear regression: SW monsoon. An analogous statistical analysis procedure is performed on samples from the SW monsoon. Three of the total of 20 samples from this season are considered separately due to the increased biological activity near the coast of Oman for those three samples.

The remote oceanic origin of most of the air masses sampled during the SW monsoon resulted in fewer detectable $\mathrm{SO}_{4}^{2-}$ sources compared to the intermonsoon. Nevertheless, we choose to start with the same variables in model 1 of Table 2 for the intermonsoon data set. Several of the independent variables, such as MSA, in model 1 of Table 3 fail the $t$-test. However, after removal of the crustal components $\mathrm{Al}$ and NSS- $\mathrm{Ca}^{2+}$, as model 2 indicates, MSA becomes more important, while the constant approaches zero, and the $\mathrm{SS}_{-} \mathrm{SO}_{4}^{2-} /$ $\mathrm{Na}^{+}$coefficient moves closer to the expected constant in ocean water $(0.252)$. The apparent negative correlation of NSS-Ca ${ }^{2+}$ with $\mathrm{SO}_{4}^{2-}$, deduced from the negative coefficient in model 1 , is most likely the result of the error associated with the small remaining NSS-Ca ${ }^{2+}$ concentrations after the large sea-salt component was subtracted from $\mathrm{Ca}^{2+}$. Evaluation of the $t$-tests in model 2 allows for the safe elimination of the constant and $\mathrm{Pb}$. In model 3 the sea-salt coefficient is ncar the expected value of 0.252 . Even though the anthropogenic component was best represented by $\mathrm{Pb}$ during the intermonsoon, $\mathrm{NO}_{3}^{-}$appears to be a better tracer during the SW monsoon. A possible reason for this is that the $\mathrm{Pb}$ signal during the $\mathrm{SW}$ monsoon is very weak, and thus more prone to errors. Nevertheless, the fact that $\mathrm{NO}_{3}^{-}$does not serve as a tracer for anthropogenic $\mathrm{SO}_{4}^{2-}$ during the intermonsoon, when continental pollution is greater and sea salt is less abundant in the atmosphere, is evidence that it cannot be used unequivocally as a tracer as such. The bio-SO ${ }_{4}^{2-} / \mathrm{MSA}$ weight ratio valid over most of the Arabian Sea during the SW monsoon is $13.5 \pm 4.4$, which is very close to the first estimate (14 \pm 3 ), when no correction for the small anthropogenic contribution was made.

The three remaining samples from the SW monsoon that were collected over coastal upwelling regions seem to display a much smaller bio-SO $\mathrm{SO}_{4}^{2-} / \mathrm{MSA}$ ratio than the rest of the sam- 
Table 4. M32/5 SW Monsoon, Three Outliers: Model Outputs From Weighted Linear Least Squares Regressions With NSS Nonanthropogenic $\mathrm{SO}_{4}^{2-}$ Being the Dependent Variables in All Cases

\begin{tabular}{lc}
\hline & Outputs \\
\hline Model summary analysis of variance & \\
$R^{2}$ & 0.991 \\
$F$ & 214.169 \\
Significance & 0.005 \\
Independent variables & MSA \\
Unstandardized coefficients $b$ & 6.802 \\
Standard error & 0.465 \\
Standardized coefficients $\beta$ & 0.995 \\
$t$ & 14.635 \\
Significance & 0.005 \\
Ninety-five percent confidence interval for $b$ & \\
Lower bound & 4.802 \\
Upper bound & 8.802 \\
\hline
\end{tabular}

For model 1. Concentrations in units $\mathrm{ng} \mathrm{m}^{-3}$. Three data points.

ples. A linear regression through three sample points is not reliable; in fact, if we retain the same variables as above, no degree of freedom to perform a regression is left, and the solution is unique. However, by subtracting from the total$\mathrm{SO}_{4}^{2-}$ the known sea-salt component and the inferred (from the other SW monsoon samples) anthropogenic component, a total of two degrees of freedom are obtained. A regression of this data set through the origin provides a bio-SO $\mathrm{S}_{4}^{2-} / \mathrm{MSA}$ ratio of $6.8 \pm 0.5$, as shown in the model output in Table 4 .

3.1.6. Temperature dependence of the bio- $\mathrm{SO}_{4}^{2-} / \mathrm{MSA}$ ratio. Although the oxidation of DMS yielding MSA and bio$\mathrm{SO}_{4}^{2-}$ appears to depend on the interplay of a series of factors [Berresheim et al., 1995; Kerminen et al., 1998a; Koga and Tanaka, 1996; Tumipseed et al., 1996], the only relevant variable measured in the present study is temperature. Thus following is a simple attempt to find a temperature dependence in the bio-SO ${ }_{4}^{2-} / \mathrm{MSA}$ weight ratio while assuming that the other variables remain unchanged.

Hynes et al. [1986] proposed that the bio- $\mathrm{SO}_{4}^{2-} / \mathrm{MSA}$ ratio should be temperature-dependent. In an attempt to find such a dependence, Bates et al. [1992] consolidated all published data (up to 1991) and plotted it as a function of air temperature. Although the compiled data exhibit considerable scatter, they seem to indicate that the $\mathrm{SO}_{4}^{2-}$ production is favored at elevated temperatures. This effect should produce larger bio$\mathrm{SO}_{4}^{2-}$ /MSA ratios at higher temperatures, as proposed by Hynes et al. [1986].

The presence of small amounts of background anthropogenic and crustal $\mathrm{SO}_{4}^{2-}$ even in remote areas as well as the collection of particles of different size ranges by different investigators will influence the bio- $\mathrm{SO}_{4}^{2-} / \mathrm{MSA}$ ratio. As a consequence, only a small number of studies can be compared directly with our data set. These include data from the remote South Pacific, Antarctica, and Tasmania, that represent samples based on the collection of aerosol particles from pollutionfree air masses over all size ranges. These data are plotted together with our current results in Figure 3 as a function of air temperature. Solid squares represent the bio-SO ${ }_{4}^{2-} / \mathrm{MSA}$ ratios extracted from linear regression analyses for the intermonsoon, SW monsoon, and the three "outliers" collected in coastal upwelling regions during the SW monsoon. Air temperatures averaged $28.9 \pm 0.6^{\circ} \mathrm{C}$ during the intermonsoon, $27.2 \pm 1.3^{\circ} \mathrm{C}$ during the SW monsoon, and $24.0 \pm 1.7^{\circ} \mathrm{C}$ in the coastal upwelling regions near the coast of Oman. Standard deviations for the ratio are estimated in the linear regression analysis, and are thus not directly comparable to standard deviations calculated from a population of samples as practiced in the literature data plotted. Three data points obtained at temperatures above $20^{\circ} \mathrm{C}$ are clearly consistent with the Hynes et al. [1986] proposition of higher $\mathrm{SO}_{4}^{2-}$ production at higher air temperatures (e.g., $1^{\circ}$ temperature gain leads to a 2.2 increase in the ratio).

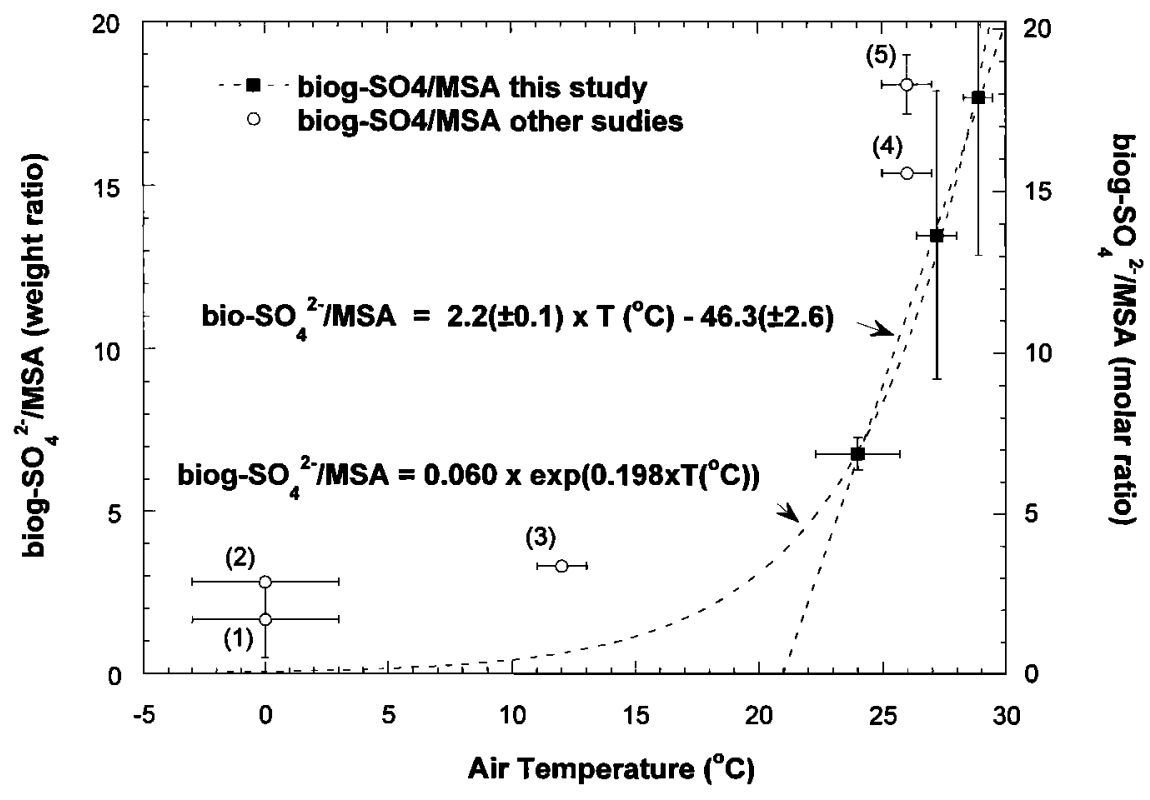

Figure 3. Bio-SO $\mathrm{SO}_{4}^{2-} / \mathrm{MSA}$ weight ratios as a function of the average daily air temperature. Figure includes data from this study (solid squares) and from literature (open circles). References: 1, Berresheim et al. [1989]; 2, Pszenny et al. [1989]; 3, Berresheim et al. [1990]; 4, Saltzman et al. [1983]; 5, Saltzman et al. [1985]. 
On the other hand, by fitting the data to an exponential temperature dependency we do observe a flattening out at lower temperatures, comparable to what has been observed in the other studies plotted in Figure 3 . The ratios observed by these investigators [Berresheim et al., 1989; Pszenny et al., 1989] at low temperatures may be elevated by the presence of uncorrected background $\mathrm{SO}_{4}^{2-}$ contributions since anthropogenic $\mathrm{SO}_{4}^{2-}$ is known to undergo long-range transport and may therefore be present at low concentrations in remote areas, such as the South Pacific and Antarctica. Furthermore, literature values for ratios at the elevated temperatures (from the South Pacific) [Saltzman et al., 1985, 1983] were not reported with daily average temperatures, thus temperatures are assumed to be $26 \pm 1^{\circ} \mathrm{C}$. Inferring from the strong temperature dependence in our data points, correct temperature ranges may have positioned those two data points in a different place. In summary, bio-SO $\mathrm{SO}_{4}^{2-} / \mathrm{MSA}$ ratios over the Arabian Sea as determined by linear regression analysis reveal a significant temperature dependence, which seems to be independent of season.

3.1.7. Sulfate sources. The standardized coefficients in a linear regression are a measure of the relative contribution of each component to the total- $\mathrm{SO}_{4}^{2-}$. Thus, from Tables 1 and 2, the biogenic contributions account for $\sim 16$ and $\sim 24 \%$ during the intermonsoon and SW monsoon, respectively, while the corresponding numbers for anthropogenic contributions are $\sim 50$ and $\sim 8 \%$. Sea salt makes up the bulk $\mathrm{SO}_{4}^{2-}$ during the SW monsoon (68\%) and $23 \%$ during the intermonsoon. While gypsum does not appear to be present during the SW monsoon, $\sim 11 \%$ of the $\mathrm{SO}_{4}^{2-}$ during the intermonsoon is attributed to gypsum.

The source of NSS- $\mathrm{Ca}^{2+}$ in the form of gypsum appears to be clearly crustal in nature since it correlates strongly with the crustal signatures in the principal component analysis presented in Table 5 (components 1 and 3). Several land-based sources may contribute to the $\mathrm{CaSO}_{4}$. Limestone, $\mathrm{CaCO}_{3}$, weathers to form an external crust of gypsum, $\mathrm{CaSO}_{4}$ :

$$
\mathrm{CaCO}_{3}(\mathrm{~s})+\mathrm{SO}_{2}(\mathrm{~g})+\mathrm{H}_{2} \mathrm{O}+1 / 2 \mathrm{O}_{2} \rightarrow \mathrm{CaSO}_{4}(\mathrm{~s})+\mathrm{H}_{2} \mathrm{CO}_{3}
$$

The most likely such crustal sources are evaporite deposits and gypsiferous soils known to exist in some regions of the Thar (India), and the deserts of Iran and Arabia [Savoie et al., 1987]. Savoie et al. [1987] found that if all the NSS-Ca were derived from gypsum, then the gypsum accounted for $\sim 10$ to $50 \%$ of the total mean NSS-SO ${ }_{4}^{2-}$ on the northeastern air masses collected over the Indian Ocean. In the present case, gypsum, as determined by linear regression, accounted for $8 \pm 7 \%$ (ranging from 0 to $23 \%$ ) of the NSS-SO ${ }_{4}^{2-}$. This is in close agreement with observations by Savoie et al., although our samples included "clean" samples from near the equator and samples representative of air masses from the northwest.

Gypsum has also been found to be the product of the reaction between acid sulfates and silicate minerals brought together by in-cloud processes [Andreae et al., 1986]. Since our samples are enriched in $\mathrm{Ca}$, over what is expected from the average crustal composition [Taylor and McLennan, 1985], this process may play a minor role in the final gypsum concentration.

NSS- $\mathrm{Ca}^{2+}$ does not appear to correlate with Al: This may be due to a combination of effects that may have led to a differential distribution of gypsum and the other crustal component. For example, the aerosol particles may have been differently sized, and/or the air parcels may have undergone distinctly different weathering cycles. Hopke [1985] noted that $\mathrm{CaSO}_{4}$ is associated with the combustion of coal, oil, and fuel and that $\mathrm{CaCO}_{3}$ is present in dust from metallurgical plants and cement plants. Although the data are inconclusive at this point, the apparent Ca enrichment may be a result of a combination of the above sources.

Results from the linear regression analyses are presented in conjunction with field observations in Figure 4. The model predictions of each source for every sample are plotted in stacked bars overlain by the dotted line representing the observed total- $\mathrm{SO}_{4}^{2-}$. Correspondence between predicted and measured total- $\mathrm{SO}_{4}^{2-}$ is quite strong, especially during the $\mathrm{SW}$ monsoon. The most noticeable discrepancies during the intermonsoon are possibly due to an overprediction of the gyp$\mathrm{SO}_{4}^{2-}$ component from the presence of other $\mathrm{Ca}^{2+}$ sources, such as $\mathrm{CaCO}_{3}$. Anion and cation equivalent charges are plotted in Figure 5. During the intermonsoon, cation charges are typically in surplus, thus, to maintain electroneutrality, a negative charge concentration corresponding to this positive surplus needs to be present. The most likely anion in this case, which is not detectable by $\mathrm{IC}$, is $\mathrm{CO}_{3}^{2-}$. Thus any nongypsum NSS- $\mathrm{Ca}^{2+}$ is assumed to be in the form of $\mathrm{CaCO}_{3}$ and presented as such in subsequent sections.

\subsection{Halogens}

Principal component analyses on the intermonsoon and SW monsoon data sets, Tables 4 and 5, respectively, reveal that $\mathrm{Cl}^{-}$ and, to a lesser degree, $\mathrm{Br}^{-}$correlate with the sea-salt component. Owing to low $\mathrm{F}^{-}$concentrations, $5.0 \pm 2.8$ and $2.1 \pm$ $1.3 \mathrm{ng} \mathrm{m}^{-3}$, for intermonsoon and $\mathrm{SW}$ monsoon, respectively, associated errors amount to 10 to $30 \%$, which is sufficiently large to exclude the $\mathrm{F}^{-}$from any further discussion.

The measured $\mathrm{Br}^{-}$(plotted in solid in Figure 6a) is near the detection limit (i.e., $\sim 15 \mathrm{ng} \mathrm{m}^{-3}$, depending on air volume sampled) throughout the whole intermonsoon season and for half of the SW monsoon samples. The hatched bars in Figure $6 \mathrm{a}$ represent the expected sea-salt-derived $\mathrm{Br}^{-}$concentrations calculated indirectly from measured $\mathrm{Na}^{+}$concentrations (according to $\mathrm{Br}^{-} / \mathrm{Na}^{+}$sea-salt ratios of Millero and Sohn [1992]). Although the error bars are of considerable magnitude, it is apparent that $\mathrm{Br}^{-}$is fully depleted, corresponding to a $100 \%$ $\mathrm{Br}^{-}$deficit in most of the samples. The samples with measurable levels of $\mathrm{Br}^{-}$occurred during the $\mathrm{SW}$ monsoon with average observed $\mathrm{Br}^{-}$deficits of $51 \pm 16 \%$ compared to the expected amount if $\mathrm{Br}^{-}$were derived only from sea salt.

Bromine has been studied in conjunction with the dramatic tropospheric ozone loss shortly after polar sunrise in the Arctic [Barrie et al., 1988; Bottenheim et al., 1990]. Bromine has been proposed in an autocatalytic reaction cycle involving transfer from the aerosol phase to gas phase as a principal free radical chain carrier that leads to $\mathrm{O}_{3}$ destruction [Fan and Jacob, 1992; McConnell et al., 1992; Vogt et al., 1996]. Vogt et al. [1996] also presented a model for an autocatalytic pathway for the production of reactive bromine and chlorine species in the pristine $\mathrm{MBL}$ involving the release of volatile species $\left(\mathrm{Br}_{2}, \mathrm{Cl}_{2}, \mathrm{BrCl}\right)$ from the particle phase:

$$
\begin{gathered}
\mathrm{H}^{+}+\mathrm{Br}^{-}+\mathrm{HOBr} \rightarrow \mathrm{Br}_{2}(\mathrm{~g})+\mathrm{H}_{2} \mathrm{O} \\
\mathrm{H}^{+}+\mathrm{Cl}^{-}+\mathrm{HOCl} \rightarrow \mathrm{Cl}_{2}(\mathrm{~g})+\mathrm{H}_{2} \mathrm{O} \\
\mathrm{H}^{+}+\mathrm{Cl}^{-}+\mathrm{HOBr} \rightarrow \mathrm{BrCl}(\mathrm{g})+\mathrm{H}_{2} \mathrm{O}
\end{gathered}
$$


Table 5. Varimax Rotated Component Matrix for Intermonsoon Samples

\begin{tabular}{|c|c|c|c|c|c|c|c|c|}
\hline & $\begin{array}{c}\text { Sampling/Analysis } \\
\text { Techniques }\end{array}$ & $\begin{array}{c}1 \\
\text { Coarse } \\
\text { Crustal }\end{array}$ & $\begin{array}{c}2 \\
\text { Sea } \\
\text { Salt }\end{array}$ & $\begin{array}{c}3 \\
\text { Fine } \\
\text { Crustal }\end{array}$ & 4 & $\begin{array}{c}5 \\
\mathrm{Fe}\end{array}$ & $\begin{array}{c}6 \\
\mathrm{Cl}^{-} \\
\text {Deficit }\end{array}$ & 7 \\
\hline Al coarse & HVDVI/ICPMS & 0.944 & 0.203 & 0.185 & -0.016 & 0.099 & 0.002 & 0.039 \\
\hline Al fine & HVDVI/ICPMS & 0.297 & -0.042 & 0.916 & 0.113 & 0.094 & -0.056 & 0.131 \\
\hline Ca coarse & HVDVI/ICPMS & 0.917 & 0.292 & 0.143 & 0.030 & 0.193 & 0.040 & 0.028 \\
\hline $\mathrm{Ca}$ fine & HVDVI/ICPMS & 0.334 & 0.138 & 0.776 & 0.362 & 0.262 & -0.035 & 0.086 \\
\hline Fe coarse & HVDVI/ICPMS & 0.385 & 0.224 & 0.061 & 0.031 & 0.791 & -0.119 & -0.041 \\
\hline Fe fine & HVDVI/ICPMS & 0.180 & 0.321 & 0.220 & -0.136 & 0.763 & 0.184 & 0.198 \\
\hline $\mathrm{K}$ coarse & HVDVI/ICPMS & 0.871 & 0.451 & 0.048 & -0.028 & 0.062 & 0.046 & 0.011 \\
\hline$K$ fine & HVDVI/ICPMS & 0.070 & 0.030 & 0.901 & -0.005 & 0.117 & 0.086 & 0.132 \\
\hline $\mathrm{Mg}$ coarse & HVDVI/ICPMS & 0.757 & 0.594 & 0.068 & -0.101 & 0.182 & -0.082 & -0.005 \\
\hline Mg fine & HVDVI/ICPMS & 0.350 & 0.354 & 0.742 & 0.292 & 0.265 & -0.051 & 0.122 \\
\hline Na coarse & HVDVI/ICPMS & 0.366 & 0.872 & -0.119 & -0.164 & 0.041 & -0.082 & -0.100 \\
\hline $\mathrm{Na}$ fine & HVDVI/ICPMS & 0.189 & 0.701 & 0.438 & 0.110 & 0.362 & 0.115 & 0.141 \\
\hline $\mathrm{Pb}$ coarse & HVDVI/ICPMS & 0.699 & -0.054 & 0.469 & -0.134 & 0.022 & 0.011 & 0.057 \\
\hline $\mathrm{Pb}$ fine & HVDVI/ICPMS & 0.459 & 0.645 & 0.489 & -0.099 & 0.019 & 0.001 & -0.009 \\
\hline Ti coarse & HVDVI/ICPMS & 0.959 & 0.119 & 0.152 & -0.002 & 0.052 & 0.013 & -0.005 \\
\hline Ti fine & HVDVI/ICPMS & 0.010 & 0.139 & 0.857 & -0.135 & -0.095 & -0.014 & -0.127 \\
\hline$V$ coarse & HVDVI/ICPMS & 0.913 & 0.157 & 0.308 & 0.007 & 0.078 & -0.018 & 0.022 \\
\hline $\mathrm{V}$ fine & HVDVI/ICPMS & 0.358 & 0.194 & 0.830 & -0.143 & 0.012 & 0.003 & -0.104 \\
\hline $\mathrm{Ca}^{2+}$ & low-volume collectors/IC & 0.720 & 0.225 & 0.506 & 0.247 & 0.037 & -0.107 & 0.232 \\
\hline $\mathrm{NSS}-\mathrm{Ca}^{2+}$ & low-volume collectors/IC & 0.723 & 0.172 & 0.513 & 0.253 & 0.029 & -0.118 & 0.232 \\
\hline $\mathrm{K}^{+}$ & low-volume collectors/IC & 0.438 & 0.796 & 0.283 & 0.216 & 0.117 & -0.036 & -0.089 \\
\hline $\mathrm{Mg}^{2+}$ & low-volume collectors/IC & 0.424 & 0.823 & 0.219 & 0.121 & 0.113 & 0.053 & 0.180 \\
\hline $\mathrm{Na}^{+}$ & low-volume collectors/IC & 0.222 & 0.926 & 0.064 & 0.010 & 0.137 & 0.095 & 0.108 \\
\hline $\mathrm{NH}_{4}^{+}$ & low-volume collectors/IC & -0.303 & 0.517 & 0.271 & -0.587 & -0.011 & -0.098 & -0.163 \\
\hline $\mathrm{NO}_{2}^{-}$ & low-volume collectors/IC & -0.024 & 0.647 & -0.105 & -0.284 & 0.327 & 0.113 & -0.254 \\
\hline $\mathrm{NO}_{3}^{-}$ & low-volume collectors/IC & 0.600 & -0.114 & 0.681 & 0.189 & -0.073 & -0.017 & -0.188 \\
\hline $\mathrm{SO}_{4}^{2-}$ & low-volume collectors/IC & 0.505 & 0.711 & 0.454 & -0.061 & 0.053 & -0.062 & -0.046 \\
\hline $\mathrm{NSS}-\mathrm{SO}_{4}^{2-}$ & low-volume collectors/IC & 0.547 & 0.588 & 0.534 & -0.077 & 0.024 & -0.104 & -0.089 \\
\hline $\mathrm{NO}_{3}^{-}+$anthr-SO ${ }_{4}^{2-}$ & low-volume collectors/IC & 0.607 & 0.439 & 0.625 & -0.027 & -0.007 & -0.024 & -0.041 \\
\hline MSA & low-volume collectors/IC & 0.088 & 0.764 & 0.279 & -0.399 & 0.096 & -0.307 & -0.137 \\
\hline $\mathrm{Cl}^{-}$ & low-volume collectors/IC & 0.220 & 0.927 & 0.075 & 0.028 & 0.154 & -0.042 & 0.094 \\
\hline $\mathrm{Cl}^{-}$deficit & low-volume collectors/IC & 0.153 & 0.589 & -0.013 & -0.086 & 0.006 & 0.737 & 0.138 \\
\hline$\% \mathrm{Cl}^{-}$deficit & low-volume collectors/IC & -0.098 & -0.305 & -0.030 & -0.103 & -0.028 & 0.849 & -0.112 \\
\hline Cat.-An. charges & low-volume collectors/IC & 0.487 & 0.189 & 0.349 & 0.226 & 0.017 & 0.278 & 0.596 \\
\hline $\mathrm{Br}^{-}$ & low-volume collectors/IC & 0.219 & 0.421 & 0.196 & 0.537 & -0.132 & 0.381 & -0.063 \\
\hline $\mathrm{F}^{-}$ & low-volume collectors/IC & 0.222 & 0.534 & -0.006 & -0.251 & -0.423 & 0.135 & -0.443 \\
\hline Acetate & low-volume collectors/IC & 0.558 & 0.000 & 0.033 & -0.022 & 0.042 & -0.637 & -0.385 \\
\hline Formate & low-volume collectors/IC & 0.019 & 0.529 & 0.140 & 0.194 & 0.666 & -0.175 & -0.185 \\
\hline Glycolate & low-volume collectors/IC & -0.048 & -0.103 & 0.108 & 0.842 & 0.069 & -0.209 & 0.062 \\
\hline Malonate & low-volume collectors/IC & 0.771 & 0.118 & 0.269 & 0.356 & 0.026 & -0.141 & -0.338 \\
\hline Oxalate & low-volume collectors/IC & 0.508 & 0.660 & 0.440 & -0.038 & 0.097 & 0.039 & 0.114 \\
\hline Wind speed, $\mathrm{m} \mathrm{s}^{-1}$ & ships meteorological data & -0.324 & 0.735 & -0.021 & 0.404 & 0.313 & -0.005 & 0.105 \\
\hline Relative humidity & ships meteorological data & -0.313 & 0.528 & -0.279 & 0.253 & 0.358 & -0.130 & 0.321 \\
\hline
\end{tabular}

Percent variance for intermonsoon samples: sample 1, 47.2; sample 2, 15.1; sample 3, 8.5; sample 4, 7.2; sample 5, 5.8; sample 6, 3.9; sample 7, 2.2. Cumulative percent: $89.7 \%$.

This led to particle phase depletion of the halides, where the bromide deficit amounted to $90 \%$ and the chloride deficit amounted to $1 \%$.

Chloride versus time (and location) is shown in Figure 6b in which the measured $\mathrm{Cl}^{-}$is compared to the expected $\mathrm{Cl}^{-}$ concentrations that were based on the observed $\mathrm{Na}^{+}$abundance, and the ratio of $\mathrm{Cl}^{-} / \mathrm{Na}^{+}$is sea salt [Millero and Sohn, 1992]. Although not as obvious as in the case of $\mathrm{Br}^{-}$, the observed $\mathrm{Cl}^{-}$is generally ( 42 out of 48 samples) below what would have been expected from the measured $\mathrm{Na}^{+}$values assuming there is no additional source of $\mathrm{Cl}^{-}$other than sea salt. The percentage $\mathrm{Cl}^{-}$deficit ranges from slightly negative to $32 \%$, whereby the largest values are encountered during the relatively more polluted intermonsoon season. These observations are in close agreement with results obtained from other open ocean regions [Graedel and Keene, 1995, and references therein].

$\mathrm{Cl}^{-}$deficits have typically been found to correlate with the proximity to continental landmasses and thus assumed to depend on the concentrations of anthropogenic pollutants such as $\mathrm{SO}_{4}^{2-}$ and $\mathrm{NO}_{3}^{-}$. In heavily polluted air masses, losses of particulate $\mathrm{Cl}^{-}$approaching $100 \%$ have been reported. On the basis of these observations it has been widely assumed that $\mathrm{Cl}^{-}$ is solely released due to the thermodynamically favorable displacement reaction between mineral acids $\left(\mathrm{H}_{2} \mathrm{SO}_{4}, \mathrm{HNO}_{3}\right)$ and $\mathrm{HCl}$ :

$$
\begin{gathered}
2 \mathrm{NaBr}(\mathrm{s})+\mathrm{H}_{2} \mathrm{SO}_{4} \rightarrow \mathrm{Na}_{2} \mathrm{SO}_{4}+2 \mathrm{HBr}(\mathrm{g}) \\
\mathrm{NaBr}(\mathrm{s})+\mathrm{HNO}_{3} \rightarrow \mathrm{NaNO}_{3}+\mathrm{HBr}(\mathrm{g}) \\
2 \mathrm{NaCl}(\mathrm{s})+\mathrm{H}_{2} \mathrm{SO}_{4} \rightarrow \mathrm{Na}_{2} \mathrm{SO}_{4}+2 \mathrm{HCl}(\mathrm{g}) \\
\mathrm{NaCl}(\mathrm{s})+\mathrm{HNO}_{3} \rightarrow \mathrm{NaNO}_{3}+\mathrm{HCl}(\mathrm{g})
\end{gathered}
$$

Kerminen et al. [1998b] also found MSA and oxalate to replace $\mathrm{Cl}^{-}$from supermicron sea-salt particles. However, since con- 


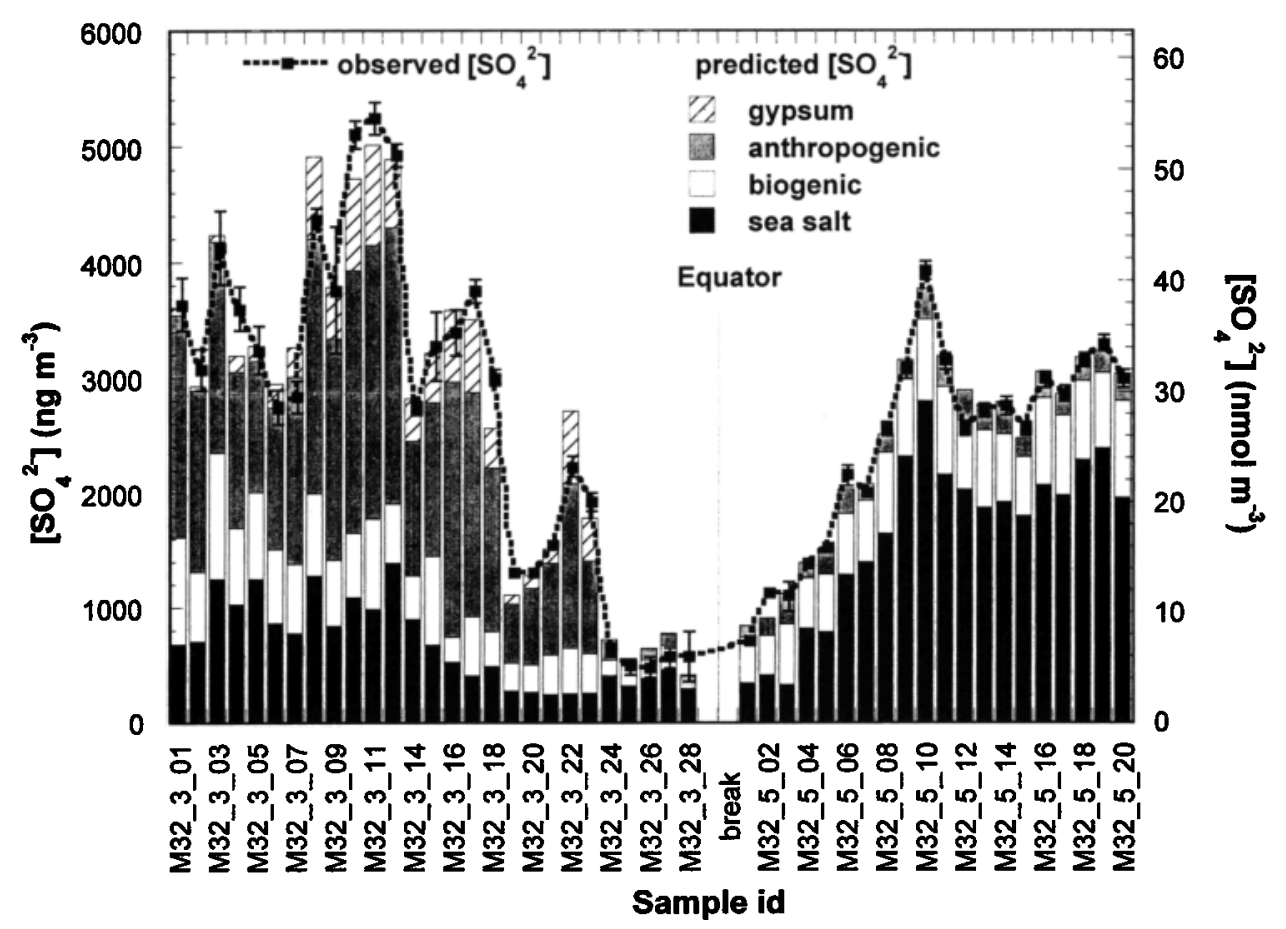

Figure 4. Observed (dotted line) and predicted (stacked bars) $\mathrm{SO}_{4}^{2-}$ versus sample. Stacked bars represent the various sources, whose proportions were determined with linear regression analysis.

centrations of latter two species are typically much lower than $\mathrm{NO}_{3}^{-}$and $\mathrm{SO}_{4}^{2-}$ combined, the $\mathrm{Cl}^{-}$released in this way should be negligible in our case.

The average $\mathrm{Cl}^{-}$deficit during the $\mathrm{SW}$ monsoon amounts to $3.5 \pm 6.3 \%$ and increases by a factor of 4.3 to $15 \pm 9 \%$ during the intermonsoon. In this particular case, the absolute deficit only increases by a factor of 1.3 (from 507 to $660 \mathrm{ng} \mathrm{m}^{-3}$ ). This value is considerably lower than the analogous factors that describe the increase of absolute concentrations of typical pollutants, such as $\mathrm{Pb}$, anthropogenic- $\mathrm{SO}_{4}^{2-}$, and $\mathrm{NO}_{3}^{-}$, which are commonly used to trace the anthropogenic contribution to the air mass. $\mathrm{Pb}$ concentrations increase by a factor of 18 from the

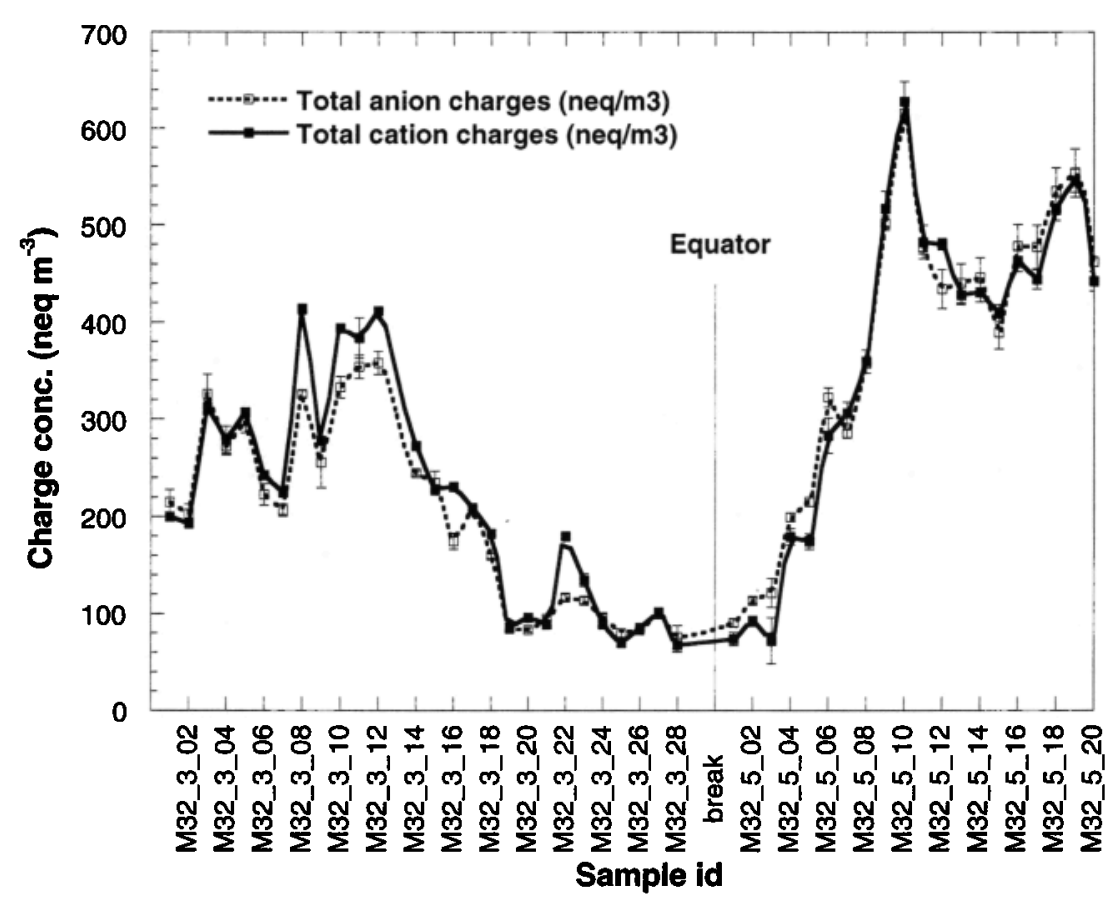

Figure 5. Total anion (dotted line) and total cation (solid line) charges versus sample, intermonsoon and SW monsoon data. 


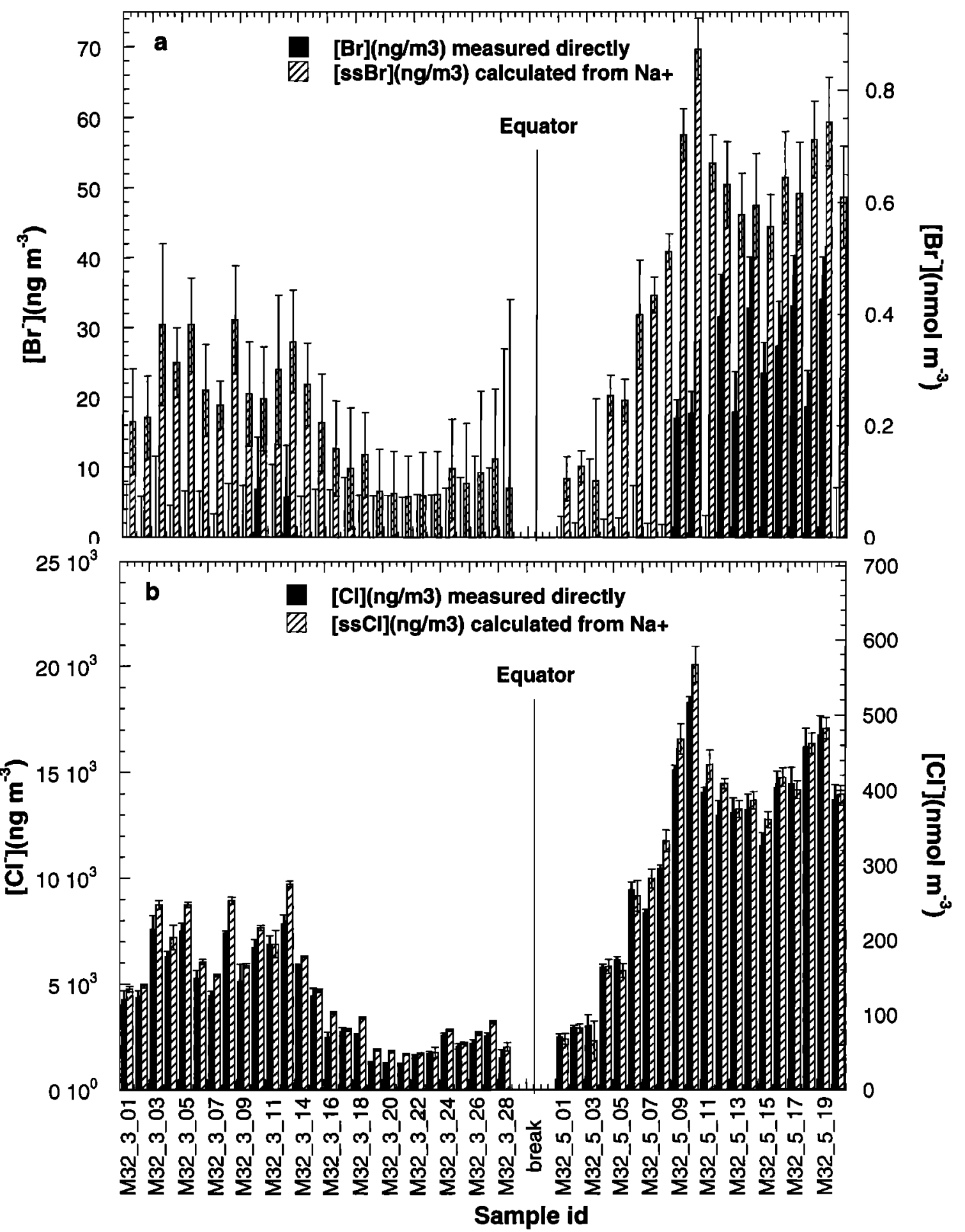

Figure 6. (a) $\mathrm{Br}^{-}, \mathrm{SS}_{-} \mathrm{Br}^{-}$and (b) $\mathrm{Cl}^{-}, \mathrm{SS}_{-} \mathrm{Cl}^{-}$during intermonsoon and $\mathrm{SW}$ monsoons, versus sample.

$\mathrm{SW}$ monsoon to the intermonsoon, while anthropogenic-SO $\mathrm{SO}_{4}^{2-}$ (as determined by multivariate linear regression analysis above) increases by a factor of 7.5 , and $\mathrm{NO}_{3}^{-}$increases by 2.6 . If the $\mathrm{Cl}^{-}$deficit is assumed to be solely due to $\mathrm{HCl}$ displacement via reactions involving strong mineral acids such as $\mathrm{H}_{2} \mathrm{SO}_{4}$ and $\mathrm{HNO}_{3}$ aerosol [McInnes et al., 1994; Sturges and Barrie, 1988], we should observe a relative deficit increase from the SW monsoon to the intermonsoon comparable to the rel- ative increase of $\mathrm{Pb}$, anthropogenic- $\mathrm{SO}_{4}^{2-}$, and $\mathrm{NO}_{3}^{-}$. This intercomparison is justifiable since the $\mathrm{Cl}^{-}$deficit does not reach $100 \%$ in any one of the samples, thus indicating that the extent of the above displacement reactions is not limited by the $\mathrm{Cl}^{-}$ concentration in the aerosol phase. Although the three anthropogenic tracers do not seem to behave in the same manner, they all display values for their concentration increases that are larger than the relative $\mathrm{Cl}^{-}$deficit increase. These observa- 


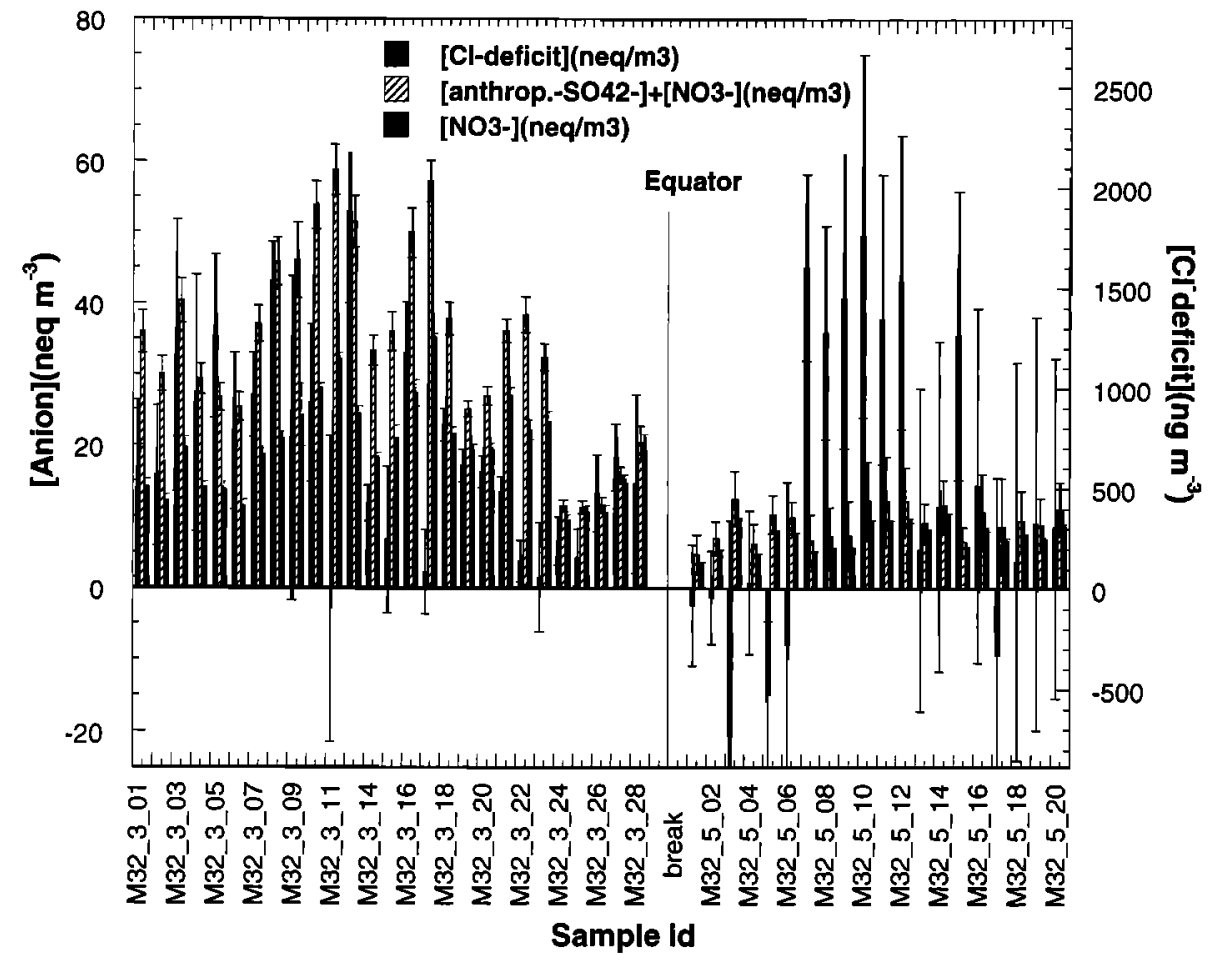

Figure 7. $\mathrm{Cl}^{-}$deficit, anthropogenic-SO $\mathrm{SO}_{4}^{2-}+\mathrm{NO}_{3}^{-}$, and $\mathrm{NO}_{3}^{-}$versus sample, intermonsoon and $\mathrm{SW}$ monsoon data.

tions suggest that additional mechanism(s) contribute to the $\mathrm{Cl}^{-}$deficit and that these mechanism(s) play a significant role especially during the SW monsoon, when pollutants are present at very low concentrations and the sea-salt contribution is predominant.

For visualization, the absolute deficit is plotted in Figure 7 in conjunction with the summed up molar equivalents of $\mathrm{NO}_{3}^{-}$ and $\mathrm{SO}_{4}^{2-}$ (i.e., $\left[\mathrm{NO}_{3}^{-}\right]+2 \times\left[\mathrm{SO}_{4}^{2-}\right]$ ). Error bars for the deficit are relatively large due to the subtraction of two large numbers, especially during the SW monsoon, when the sea-salt contribution is 2.5 times that encountered during the intermonsoon. Nevertheless, seasonal distinctions in the data set can be recognized. Although the $\mathrm{Cl}^{-}$deficit during the intermonsoon is typically within the range of the anthropogenic pollutants plotted, no obvious correlation between the two is observed. This may be due to some amount of externally mixed anthropogenic and sea-salt particles. However, most $\mathrm{NO}_{3}^{-}$and some NSS-SO $\mathrm{S}_{4}^{2-}$ is expected to be associated with the sea-salt particles [Bassett and Seinfeld, 1984; Berresheim et al., 1991; Huebert et al., 1996; Keene et al., 1998; Mclnnes et al., 1994; Natk et al., 1991; O'Dowd et al., 1997; Savoie and Prospero, 1982; Sievering et al., 1990; Sisterson, 1989] and thus available for $\mathrm{Cl}^{-}$depletion. Different observations are made during the SW monsoon, when the $\mathrm{Cl}^{-}$deficit ranges from negative to large positive values that do not match concentrations of anthropogenic pollutants. Even if all the particles were internally mixed during the SW monsoon, there would not be enough $\mathrm{NO}_{3}^{-}$and $\mathrm{NSS}_{-} \mathrm{SO}_{4}^{2-}$ available to account for the large $\mathrm{Cl}$ deficit observed. Thus there may be an indication of different prevalent mechanisms during each of the seasons.

Principal component analyses presented in Tables 4 and 5 reconfirm the poor correlation between the observed $\mathrm{Cl}^{-}$deficit on one hand and the anthropogenic- $\mathrm{SO}_{4}^{2-}$ and $\mathrm{NO}_{3}^{-}$on the other for both the intermonsoon and the SW monsoon, respectively. During the intermonsoon, the $\mathrm{Cl}^{-}$deficit does not seem to correlate with any of the major principal components and appears isolated in component 6 of Table 5. On the other hand, during the SW monsoon, the $\mathrm{Cl}^{-}$deficit seems to correlate with the charge difference observed between anions and cations in component 4 of Table 6 . The discrepancy between the summations of measured anionic and cationic charges is most likely due to species that are undetectable by the IC, such as $\mathrm{H}^{+}$and $\mathrm{CO}_{3}^{2-}$. Total anion and cation charges are plotted simultaneously in Figure 5.

Volatilized $\mathrm{Cl}^{-}$in the form of $\mathrm{HCl}$ from acid displacement reactions with $\mathrm{H}_{2} \mathrm{SO}_{4}$ and/or $\mathrm{HNO}_{3}$ would have been replaced by the corresponding $\mathrm{SO}_{4}^{2-}$ and $\mathrm{NO}_{3}^{-}$anions and thus been detected by IC. On the other hand, the alternative idea for the release of $\mathrm{Cl}$ in the form of reactive species, such as $\mathrm{HOCl}$, $\mathrm{ClNO}_{2}$, and $\mathrm{BrCl}$, may not be replaced by a detectable anion. If no other significant source of $\mathrm{CO}_{3}^{2-}$ (e.g., in the form of calcite) is present in the aerosol phase as is the case during the SW monsoon, it is conceivable that the charge difference may become a mcasure of the extent of $\mathrm{Cl}^{-}$released in this form.

A correlation between the $\mathrm{Cl}^{-}$deficit and the apparent charge difference during the "clean" SW monsoon is apparent in Figure 8, where the absolute concentration difference between anion and cation charges is plotted as a function of $\mathrm{Cl}^{-}$ deficit. Error bars are relatively large due to repeated propagation of error for every calculation; nonetheless, a distinct difference between the scattered intermonsoon and the aligned SW monsoon samples is apparent.

In summary, observations seem to indicate that $\mathrm{Cl}^{-}$released by acid displacement reactions does not adequately describe the observed $\mathrm{Cl}^{-}$deficits for the two sampling seasons. While the acid displacement reaction most likely is of some impor- 
Table 6. Varimax Rotated Component Matrix for SW Monsoon Samples

\begin{tabular}{|c|c|c|c|c|c|c|c|c|}
\hline & $\begin{array}{l}\text { Sampling/Analysis } \\
\text { Techniques }\end{array}$ & $\begin{array}{c}1 \\
\text { Sea } \\
\text { Salt }\end{array}$ & $\begin{array}{c}2 \\
\text { Coarse } \\
\text { Crustal }\end{array}$ & $\begin{array}{c}3 \\
\text { Fine } \\
\text { Crustal }\end{array}$ & $\begin{array}{c}4 \\
\mathrm{Cl}^{-} \\
\text {Deficit }\end{array}$ & $\begin{array}{c}5 \\
\text { MSA, } \\
\mathrm{V}\end{array}$ & $\begin{array}{c}6 \\
\text { Anthropogenic }\end{array}$ & 7 \\
\hline Al coarse & HVDVI/ICPMS & 0.219 & 0.914 & 0.221 & 0.064 & 0.137 & 0.122 & -0.043 \\
\hline Al fine & HVDVI/ICPMS & 0.325 & 0.237 & 0.836 & -0.029 & 0.220 & 0.204 & 0.078 \\
\hline Ca coarse & HVDVI/ICPMS & 0.348 & 0.869 & 0.130 & 0.219 & 0.199 & 0.084 & 0.053 \\
\hline $\mathrm{Ca}$ fine & HVDVI/ICPMS & 0.670 & 0.272 & 0.498 & 0.252 & 0.367 & 0.012 & -0.050 \\
\hline Fe coarse & HVDVI/ICPMS & 0.179 & 0.930 & 0.200 & 0.018 & 0.112 & 0.147 & -0.035 \\
\hline Fe fine & HVDVI/ICPMS & 0.250 & 0.148 & 0.837 & -0.045 & 0.081 & 0.342 & 0.114 \\
\hline $\mathrm{K}$ coarse & HVDVI/ICPMS & 0.356 & 0.891 & 0.040 & 0.100 & 0.133 & 0.034 & 0.128 \\
\hline$K$ fine & HVDVI/ICPMS & 0.815 & 0.211 & 0.376 & 0.113 & 0.222 & 0.085 & 0.083 \\
\hline Mg coarse & HVDVI/ICPMS & 0.383 & 0.846 & -0.018 & 0.147 & 0.226 & 0.106 & 0.153 \\
\hline Mg fine & HVDVI/ICPMS & 0.828 & 0.253 & 0.307 & 0.094 & 0.312 & 0.016 & 0.135 \\
\hline Na coarse & HVDVI/ICPMS & 0.360 & 0.880 & -0.039 & 0.109 & 0.153 & 0.036 & 0.177 \\
\hline $\mathrm{Na}$ fine & HVDVI/ICPMS & 0.829 & 0.267 & 0.296 & 0.067 & 0.305 & -0.031 & 0.111 \\
\hline $\mathrm{Pb}$ coarse & HVDVI/ICPMS & 0.382 & 0.736 & 0.061 & -0.177 & -0.221 & -0.078 & -0.127 \\
\hline $\mathrm{Pb}$ fine & HVDVI/ICPMS & -0.256 & 0.168 & 0.449 & -0.331 & 0.013 & 0.636 & -0.038 \\
\hline Ti coarse & HVDVI/ICPMS & 0.046 & 0.954 & 0.115 & -0.025 & -0.004 & 0.064 & -0.132 \\
\hline Ti fine & HVDVI/ICPMS & 0.083 & 0.170 & 0.863 & -0.357 & 0.011 & 0.022 & -0.099 \\
\hline $\mathrm{V}$ coarse & HVDVI/ICPMS & 0.010 & 0.290 & 0.314 & -0.154 & 0.037 & -0.104 & 0.848 \\
\hline$V$ fine & HVDVI/ICPMS & 0.268 & 0.013 & 0.253 & -0.058 & 0.896 & 0.074 & 0.073 \\
\hline $\mathrm{Ca}^{2+}$ & low-volume collectors/IC & 0.669 & 0.439 & 0.334 & 0.323 & 0.263 & 0.007 & -0.239 \\
\hline NSS-Ca ${ }^{2+}$ & low-volume collectors/IC & 0.430 & 0.438 & 0.480 & 0.356 & 0.321 & -0.044 & -0.340 \\
\hline $\mathrm{K}^{+}$ & low-volume collectors/IC & 0.842 & 0.343 & -0.006 & 0.354 & 0.107 & 0.108 & -0.001 \\
\hline $\mathrm{Mg}^{2+}$ & low-volume collectors/IC & 0.882 & 0.361 & 0.081 & 0.179 & 0.168 & 0.004 & -0.050 \\
\hline $\mathrm{Na}^{+}$ & low-volume collectors/IC & 0.886 & 0.352 & 0.090 & 0.214 & 0.133 & 0.045 & -0.021 \\
\hline $\mathrm{NH}_{4}^{+}$ & low-volume collectors/IC & -0.056 & -0.146 & 0.803 & 0.382 & 0.067 & 0.057 & 0.214 \\
\hline $\mathrm{NO}_{2}^{-}$ & low-volume collectors/IC & 0.189 & -0.098 & -0.047 & 0.305 & -0.360 & 0.253 & 0.692 \\
\hline $\mathrm{NO}_{3}^{-}$ & low-volume collectors/IC & 0.284 & 0.137 & 0.440 & -0.073 & 0.299 & 0.683 & 0.018 \\
\hline $\mathrm{SO}_{4}^{2-}$ & low-volume collectors/IC & 0.898 & 0.353 & 0.063 & 0.117 & 0.133 & 0.140 & 0.025 \\
\hline NSS-SO ${ }_{4}^{2-}$ & low-volume collectors/IC & 0.664 & 0.247 & -0.071 & -0.319 & 0.092 & 0.490 & 0.210 \\
\hline $\mathrm{NO}_{3}^{-}+$anthr- $\mathrm{SO}_{4}^{2-}$ & low-volume collectors/IC & 0.281 & 0.158 & 0.476 & -0.082 & 0.023 & 0.694 & 0.060 \\
\hline MSA & low-volume collectors/IC & 0.408 & 0.157 & -0.002 & -0.003 & 0.836 & 0.144 & -0.087 \\
\hline $\mathrm{Cl}^{-}$ & low-volume collectors/IC & 0.897 & 0.362 & 0.114 & 0.101 & 0.151 & 0.032 & -0.044 \\
\hline $\mathrm{Cl}^{-}$deficit & low-volume collectors/IC & 0.423 & 0.134 & -0.095 & 0.811 & -0.036 & 0.104 & 0.131 \\
\hline$\% \mathrm{Cl}^{-}$deficit & low-volume collectors/IC & 0.507 & 0.051 & -0.304 & 0.703 & 0.090 & -0.273 & 0.136 \\
\hline Cat.-An. charges & low-volume collectors/IC & 0.271 & 0.166 & 0.043 & 0.904 & 0.040 & -0.103 & -0.049 \\
\hline $\mathrm{Br}^{-}$ & low-volume collectors/IC & 0.526 & 0.260 & 0.273 & 0.047 & 0.352 & -0.228 & -0.483 \\
\hline $\mathrm{F}^{-}$ & low-volume collectors/IC & 0.106 & -0.164 & 0.728 & -0.469 & -0.022 & 0.176 & 0.280 \\
\hline Acetate & low-volume collectors/IC & -0.065 & -0.017 & 0.399 & -0.638 & -0.037 & 0.433 & 0.282 \\
\hline Formate & low-volume collectors/IC & 0.453 & 0.290 & 0.726 & 0.079 & -0.029 & 0.074 & -0.139 \\
\hline Glycolate & low-volume collectors/IC & 0.333 & 0.186 & 0.681 & -0.263 & 0.263 & 0.224 & -0.177 \\
\hline Malonate & low-volume collectors/IC & 0.417 & 0.318 & 0.232 & 0.275 & 0.669 & 0.087 & -0.291 \\
\hline Oxalate & low-volume collectors/IC & 0.651 & 0.334 & 0.175 & 0.322 & 0.058 & 0.477 & 0.097 \\
\hline Wind speed, $\mathrm{m} \mathrm{s}^{-1}$ & ships meteorolog & 0.823 & -0.084 & 0.312 & 0.150 & 0.202 & 0.136 & -0.103 \\
\hline Relative humidity & ships meteorological data & 0.513 & 0.320 & -0.062 & 0.070 & 0.688 & -0.045 & -0.293 \\
\hline
\end{tabular}

Percent variance for SW monsoon samples: sample 1, 47.6; sample 2, 15.8; sample 3, 9.6; sample 4, 7.1; sample 5, 5.4; sample 6, 3.6; sample 7, 3.1. Cumulative percent: $92.1 \%$.

tance during the more highly polluted intermonsoon, this reaction seems negligible during the sea-salt-influenced SW monsoon, when $\mathrm{Cl}^{-}$deficits are observed but anthropogenic inputs are minimal.

\subsection{Organic Anions}

Increased interest in organic anions in the atmosphere stems from the hygroscopicity of these ions. Organic aerosols have been shown active in the formation of $\mathrm{CCN}$ comparable to some inorganic aerosols [Cruz and Pandis, 1998; Matsumoto et al., 1997]. Novakov and Penner [1993] found that organic aerosol mass dominated the total mass in nucleation mode in a marine site known to be influenced by anthropogenic emissions. Even though in summation the organic anions may amount to only a minute fraction of the total ions in atmospheric aerosol, they may be relevant to the formation of new particles in the atmosphere. Furthermore, organic anions have been shown to play a major role in photochemically reducing insoluble $\mathrm{Fe}(\mathrm{III})$ to release soluble $\mathrm{Fe}(\mathrm{II})$ [Faust and Zepp, 1993; Pehkonen et al., 1993; Siefert et al., 1994]. This is a topic of interest in our preceding paper [Siefert et al., 1999] where soluble $\mathrm{Fe}$ (II) was determined over the ocean in the context of the iron hypothesis [Martin et al., 1994; Martin and Fitzwater, 1988; Martin et al., 1991].

In the present samples, organic anions represent only $3.1 \pm$ $2.2 \mathrm{wt} \%(2.2 \pm 2.2 \mathrm{~mol} \%)$ of all the anions analyzed during the intermonsoon, while the corresponding numbers for the SW monsoon are $1.5 \pm 0.6 \mathrm{wt} \%(0.8 \pm 0.4 \mathrm{~mol} \%)$. Since no simultaneous CNN measurements were undertaken during this sampling program, this data cannot be interpreted in light of findings presented above. Instead, further discussion will focus on the relative distribution and sources of each of the organic anions measured.

In Figure 9, acetate, glycolate, formate, malonate, and oxalate are plotted as a function of sample for both the intermonsoon and the SW monsoon seasons. Acetic and formic 


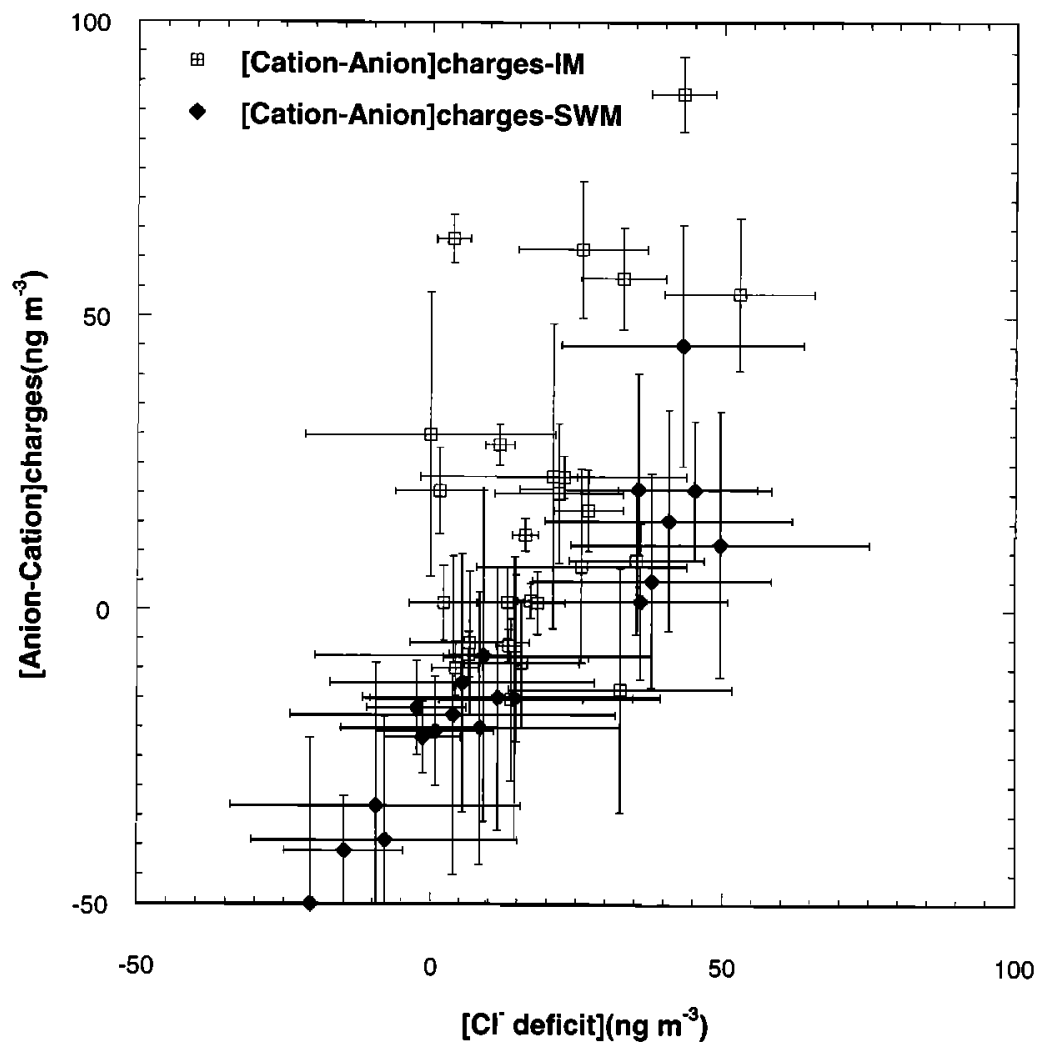

Figure 8. Anion minus cations charges versus $\mathrm{Cl}^{-}$deficit during intermonsoon (open squares) and SW monsoon (solid diamonds).

acids are typically more abundant in the aqueous and gaseous phases than in aerosol particles. As a result, one may expect introduction of sampling artifacts during collection as these gaseous species may be trapped on the cake of sea salt formed on the filter. Thus their measured aerosol concentrations may not be easily interpretable. In an attempt to determine their sources, both acetate and formate are included in the principal component analyses in Tables 4 and 5 for the intermonsoon and SW monsoon, respectively.

During the intermonsoon, acetate shows some correlation with the coarse crustal component, which, based on the scores for $\mathrm{Pb}, \mathrm{V}, \mathrm{NO}_{3}^{-}$, and NSS-SO ${ }_{4}^{2-}$, is also found to include some fraction of anthropogenic material. Similar observations are made during the SW monsoon where acetate correlates slightly with the fine crustal component, which also includes some anthropogenic material; in addition, it correlates with component 6 , which is purely anthropogenic. Thus indications are that acetic acid is anthropogenically derived, but this does not exclude the presence of other, weaker sources that remain undetected by principal component analysis. Of special interest is that acetate anticorrelates with the $\mathrm{Cl}^{-}$deficit in samples from both the intermonsoon and SW monsoon. No explanation can be given for that.

In contrast, formate correlates somewhat with the sea-salt component during both seasons. In addition, formate seems associated with anthropogenic emissions, since it correlates with components in the two seasons that carry anthropogenic signatures: the iron component (5) during the intermonsoon, which was determined in our previous paper [Siefert et al., 1999] to possibly be contamination from the ship's plume, and the fine crustal component during the SW monsoon, which includes an anthropogenic fraction. Thus formate may have a biogenic source, similar to MSA, in addition to an anthropogenic one.

Malonate and oxalate are both dicarboxylic acids, which, due to the presence of two carboxylic groups, are less volatile and are mostly present in the particle phase in the ambient atmosphere. Oxalic acid has been observed to be the dominant dicarboxylic acid in many urban areas [Kawamura and Ikushima, 1993, and references therein] and was found to be produced secondarily in the atmosphere by photochemically induced reactions involving organic precursors. Kawamura and Ikushima's [1993] study suggests that diacids once produced in the atmosphere are further oxidized to result in smaller diacids, leading to the accumulation of oxalic acid. Thus we expect oxalic acid to correlate with the anthropogenic component. The principal component analysis reveals that oxalate is mainly associated with the sea salt during both seasons, comparable to formate. In addition, during the intermonsoon oxalate also correlates with the fine crustal component that carries an anthropogenic fingerprint, as mentioned above, and during the SW monsoon, with component 6 , the ant hropogenic one. Thus, besides the anthropogenic source, other factors, such as the aerosol residence time in the air and the aerosol matrix composition, may play important roles in the final oxalate concentrations measured during both seasons.

Malonate displays a different behavior from oxalate. It correlates with the coarse crustal component during the intermonsoon, but with the sea-salt and the MSA component during the $\mathrm{SW}$ monsoon. Thus malonate seems to have a biogenic source, especially during the SW monsoon.

In summary, carboxylic acids over the Arabian Sea during 

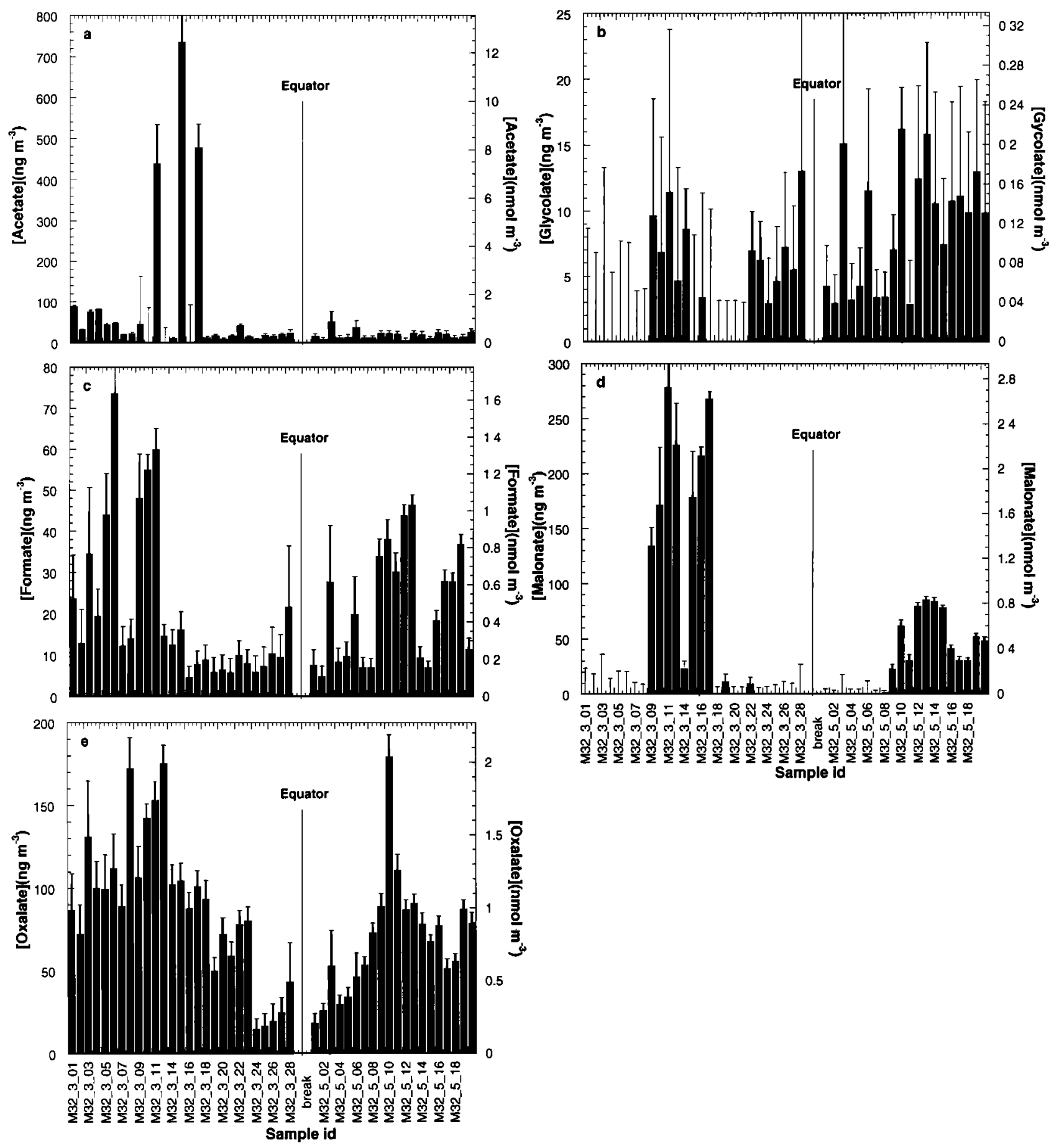

Figure 9. Organic anions versus sample: (a) acetate, (b) glycolate, (c) formate, (d) malonate, and (e) oxalate.

the intermonsoon and SW monsoon seem to be of both anthropogenic and biogenic nature. Because carboxylic acids may be directly emitted as well as produced from organic precursors, their measured concentrations also become a function of parameters such as the residence time in the atmosphere and the presence of precursors and reactive species. Once formed, carboxylic acids are removed from the atmosphere mainly by dry and wet deposition; this is due to their weak reactivity in the atmosphere. All these factors play a role in determining the final concentration of carboxylic acids, and thus determining their sources based on the principal component analysis is not conclusive.

\subsection{Cations}

Water-soluble fractions of $\mathrm{Na}^{+}, \mathrm{K}^{+}, \mathrm{Mg}^{2+}, \mathrm{Ca}^{2+}$, and $\mathrm{NH}_{4}^{+}$ were quantified by IC. $\mathrm{NH}_{3}$ is mainly released in conjunction with agriculture and farming, but over the oceans, some $\mathrm{NH}_{3}$ is biogenically derived. Gaseous $\mathrm{NH}_{3}$ reacts with sulfate aerosol 


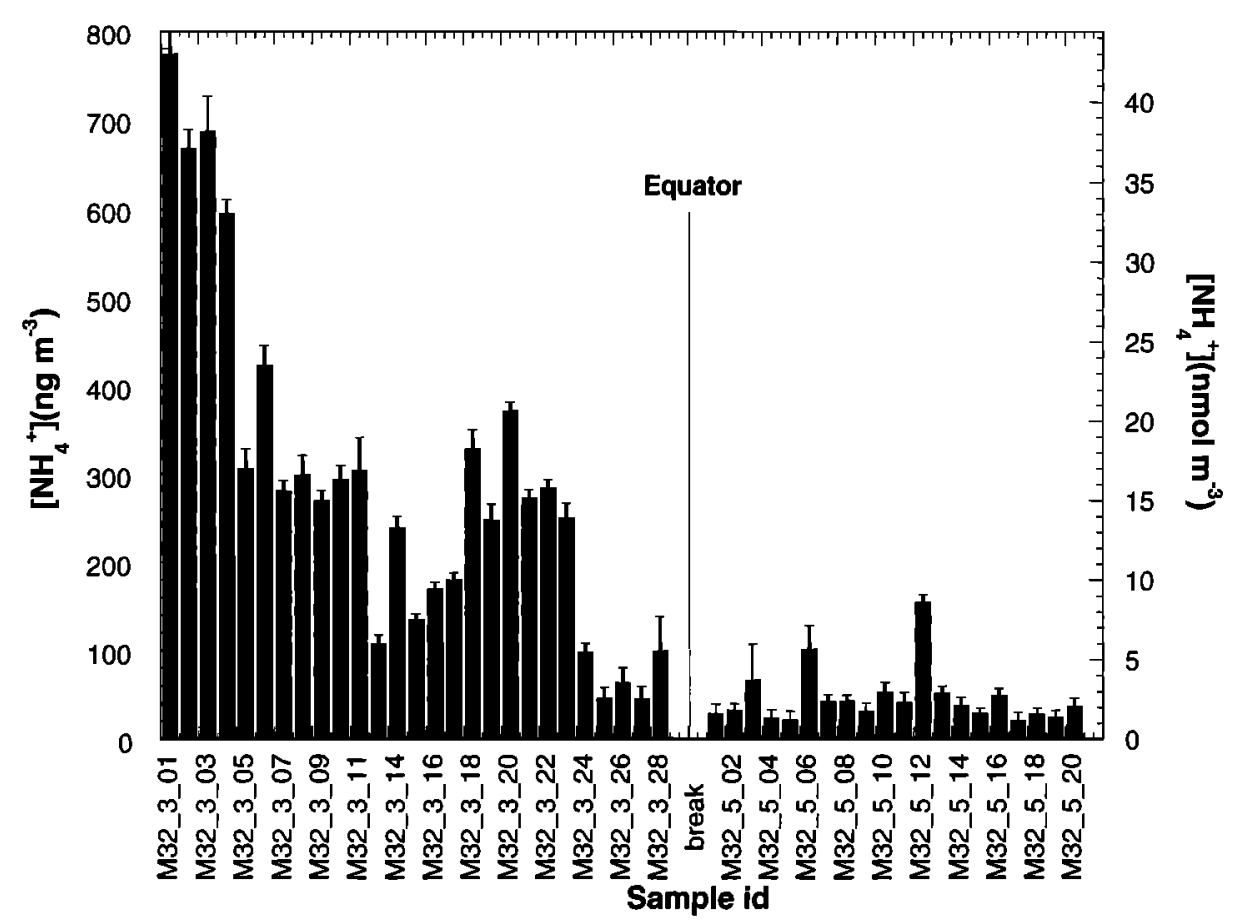

Figure 10. $\mathrm{NH}_{4}^{+}$versus sample during intermonsoon and $\mathrm{SW}$ monsoon.

particles thereby neutralizing the medium. Since both $\mathrm{NH}_{3}$ and anthropogenically derived $\mathrm{SO}_{4}^{2-}$ are transported from the continents to the ocean, $\mathrm{NH}_{4}^{+}$is expected to vary in conjunction with anthr- $\mathrm{SO}_{4}^{2-}$. However, during the intermonsoon, which is heavily influenced by continental sources, such a correlation is not obvious; instead, $\mathrm{NH}_{4}^{+}$seems to correlate with the sea-salt component in the principal component analysis in Table 5. A plot of concentration versus sample for $\mathrm{NH}_{4}^{+}$during the intermonsoon, Figure 10, shows increased $\mathrm{NH}_{4}^{+}$concentrations with continental proximity; nevertheless, no relationship between anthr- $\mathrm{SO}_{4}^{2-}$ and $\mathrm{NH}_{4}^{+}$is found. The larger concentrations observed near the coast may be due to the combination of increased $\mathrm{NH}_{3}$ production in near-shore environments and the short lifetime of $\mathrm{NH}_{3}$ [Schlesinger and Hartley, 1992].

The $\mathrm{NH}_{4}^{+}$/anthr-SO $\mathrm{SO}_{4}^{2-}$ equivalent mol ratio (anthr- $\mathrm{SO}_{4}^{2-}$ is determined in the linear regression analysis above) during the intermonsoon varies between 0.2 and 5.0 (average value: $1.8 \pm$ 1.2). This indicates that most of the anthr- $\mathrm{SO}_{4}^{2-}$ is neutralized by $\mathrm{NH}_{3}$. Both $\left(\mathrm{NH}_{4}\right)_{2} \mathrm{SO}_{4}$ and some $\mathrm{NH}_{4} \mathrm{HSO}_{4}$ are expected present in these aerosol particles. In the cases where the ratios is larger than 2 , more $\mathrm{NH}_{3}$ is assimilated by the particle than necessary for full neutralization. When such surplus of $\mathrm{NH}_{4}^{+}$is detected, the formation and maintenance of particulate $\mathrm{NH}_{4} \mathrm{NO}_{3}$ may become possible. However, due to the high temperatures encountered in the present samples, at which $\mathrm{NH}_{4} \mathrm{NO}_{3}$ becomes thermodynamically unstable, its presence is highly unlikely. Instead, biogenically derived $\mathrm{SO}_{4}^{2-}$ may be considered to add acidity to the aerosol and therefore be neutralized by available $\mathrm{NH}_{3}$. The equivalent mol ratio of $\mathrm{NH}_{4}^{+}$/ (anthr + bio) $-\mathrm{SO}_{4}^{2-}$ also varies from 0.2 to 5.0 (average value: $1.1 \pm 0.9$ ).

During the SW monsoon, average $\mathrm{NH}_{4}^{+}$concentrations $\left(46 \pm 32 \mathrm{ng} \mathrm{m}^{-3}\right)$ are lower by more than a factor of $6 \mathrm{com}$ pared to the intermonsoon, and $\mathrm{NH}_{4}^{+}$correlates strongly with the fine crustal component in the principal component analysis in Table 6. Since this fine crustal component includes an anthropogenic signal, it is likely that the $\mathrm{NH}_{4}^{+}$originates from the continents. The SW monsoon is characterized by clean marine air masses, with a relatively large input of biogenically derived $\mathrm{SO}_{4}^{2-}$. Thus the small quantities of $\mathrm{NH}_{3}$ will not suffice for neutralization of both anthropogenic and biogenic $\mathrm{SO}_{4}^{2-}$. This is revealed in the small equivalent mol ratio $\mathrm{NH}_{4}^{+} /($anthr + bio) $-\mathrm{SO}_{4}^{2-}$ observed during this season: it varies from 0.1 to 1.0 with an average of $0.3 \pm 0.2$. Thus most of the $\mathrm{SO}_{4}^{2-}$ during this season seems to be present as $\mathrm{H}_{2} \mathrm{SO}_{4}$ and $\mathrm{HSO}_{4}^{2-}$.

$\mathrm{Na}^{+}, \mathrm{K}^{+}$, and $\mathrm{Mg}^{2+}$ are usually expected to be conservative tracers of sea salt, while $\mathrm{Ca}^{2+}$ may have additional sources, such as continentally derived gypsum or oceanic $\mathrm{CaCO}_{3}$. However, as Keene et al. [1986] illustrated, the correct choice for the sea-salt tracer needs to be carefully evaluated. They conclude from their database that $\mathrm{Na}^{+}$or $\mathrm{Mg}^{2+}$ are the best tracers, but that the specific data set has to be evaluated, and the element with the lower concentration relative to sea salt picked.

Plate 1 depicts the four cations, as dotted lines, in conjunction with concentrations for the same elements determined with ICP-MS and from the high-volume collector filters. Initial focus is on the dotted lines. Comparing these lines in the four plots reveals the similarity between $\mathrm{Na}^{+}$(Plate 1a) and $\mathrm{Mg}^{2+}$ (Plate $1 \mathrm{~b}$ ), especially during the SW monsoon, when high wind speeds (up to $16 \mathrm{~m} \mathrm{~s}^{-1}$, with $11 \mathrm{~m} \mathrm{~s}^{-1}$ average, as opposed to $7 \mathrm{~m} \mathrm{~s}^{-1}$ average during the intermonsoon) are responsible for elevated abundance of sea-salt particles in the atmosphere. Since $\mathrm{Mg}^{2+}$ seems to exhibit slightly larger concentrations during the intermonsoon compared to $\mathrm{Na}^{+}$, relative to sea salt, $\mathrm{Na}^{+}$is assumed to be the better sea-salt tracer. The same reasoning holds true for the ICP-MS data, presented in stacked bars.

Thus, after accounting for the crustal contribution to $\mathrm{Na}$ (ICP-MS), using $\mathrm{Al}$ as the tracer and average crustal concentrations from Taylor and McLennan [1985], the rest of $\mathrm{Na}$ is 

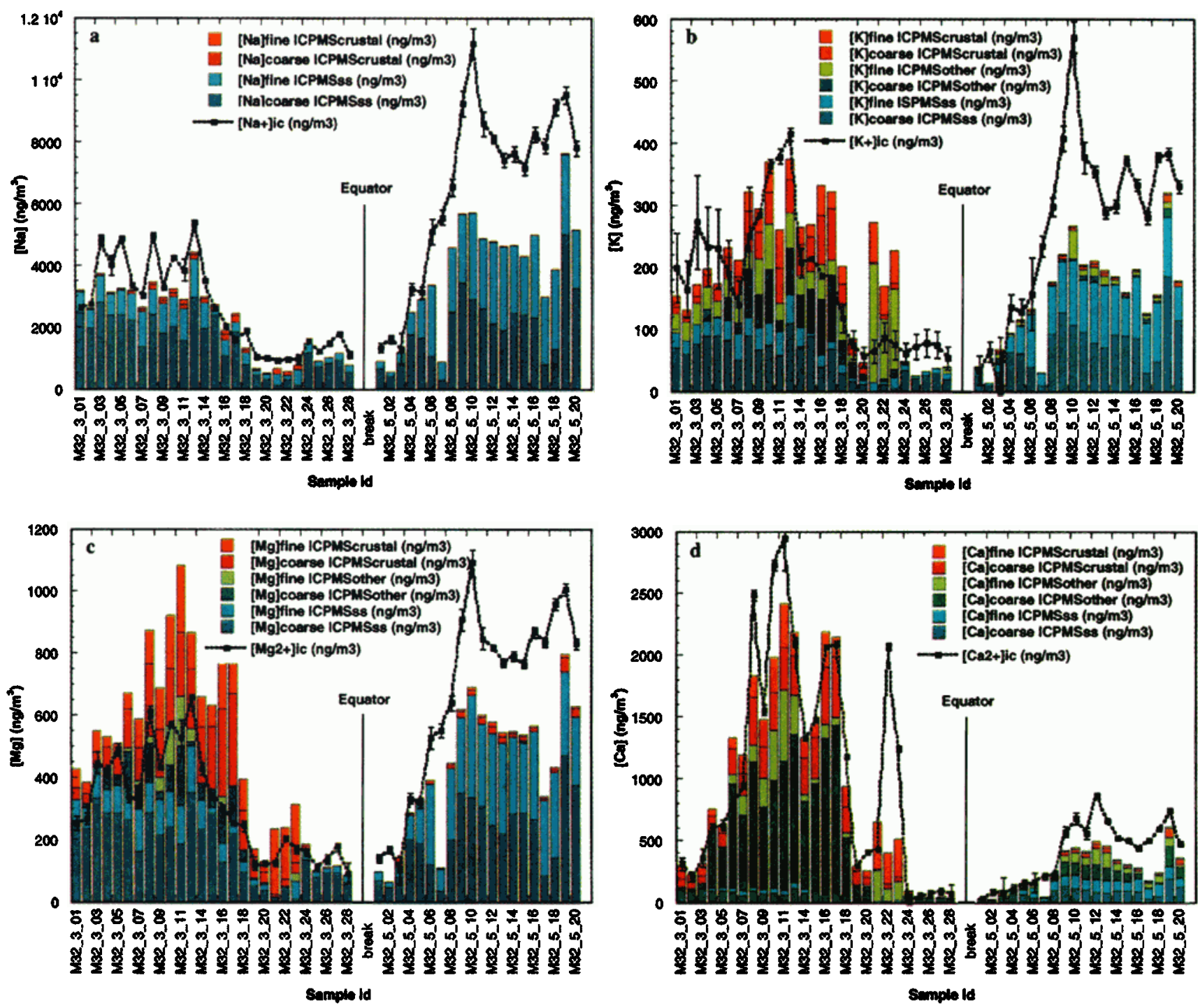

Plate 1. (a) $\mathrm{Na}$, (b) $\mathrm{K}$, (c) $\mathrm{Mg}$, and (d) $\mathrm{Ca}$ as detected with IC (dotted lines) and ICMPS (stacked bars) versus intermonsoon and SW monsoon samples. See text for description on how proportions of stacked bars were determined.

assumed to be sea-salt-derived. This SS-Na is further utilized to estimate sea-salt contributions of $\mathrm{Mg}, \mathrm{K}$, and $\mathrm{Ca}$, based on sea-salt concentrations by Millero and Sohn [1992]. In this manner, sea-salt, crustal, and remaining (denoted "other") contributions to $\mathrm{Na}, \mathrm{Mg}, \mathrm{K}$, and $\mathrm{Ca}$ are determined and plotted in stacked bars in Plate 1.

When comparing the total concentrations of $\mathrm{Na}, \mathrm{Mg}, \mathrm{K}$, and $\mathrm{Ca}$ with the corresponding ions in Plates 1a, 1b, 1c, and 1d, respectively, one has to keep in mind that the two data sets are derived from two different collectors and two different analysis techniques. Furthermore, the strong acid digestion performed for samples analyzed by ICP-MS assures a comprehensive inclusion of the elements independent of their initial form. Thus the water soluble fraction is a portion of the total concentration as determined by ICP-MS. If collector efficiencies were identical, the dotted line, representing the soluble fraction, would necessarily fall within the concentrations determined by ICP-MS; however, this is not the case. The discrepancy is less during the intermonsoon than during the SW monsoon, most probably as a function of wind speed. It is conceivable that at larger wind speeds the high-volume dichotomous virtual impactor is less efficient in collecting the large particles, which are typically composed of sea salt. Thus, during the SW monsoon, when sources other than sea salt are scarce, the dotted line, representing the soluble fraction, is above the stacked bars.

$\mathrm{Ca}$ in Plate 1d displays a very different pattern compared to the other three elements. While the signature during the SW monsoon is similar to the other three metals, during the intermonsoon, both the $\mathrm{Ca}^{2+}$ and the total $\mathrm{Ca}$ concentrations are larger by a factor of 6 compared to what would be expected if Ca behaved similar to the other elements. After subtracting the crustal and sea-salt components, as explained above, the remaining ICP-MS Ca (represented in green stacked bars) is substantial and mostly present in the coarse size fraction $(>3$ $\mu \mathrm{m})$; furthermore, this extra $\mathrm{Ca}$ must be water-soluble since the same enrichment is observed for $\mathrm{Ca}^{2+}$. Thus indications are that this extra $\mathrm{Ca}$ is present in the form of gypsum, possibly carried directly from gypsiferous continental soils [Esteve et al., 1997; Hoornaert et al., 1996; Savoie et al., 1987; Zhou and 
(a) Intermonsoon

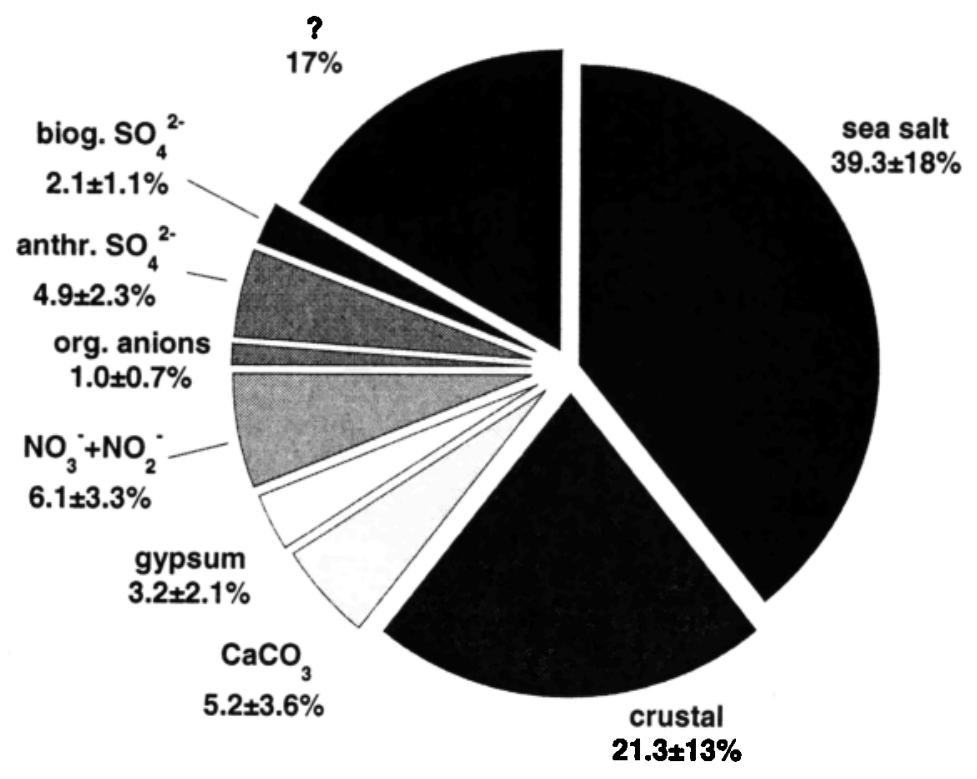

(b) sW monsoon

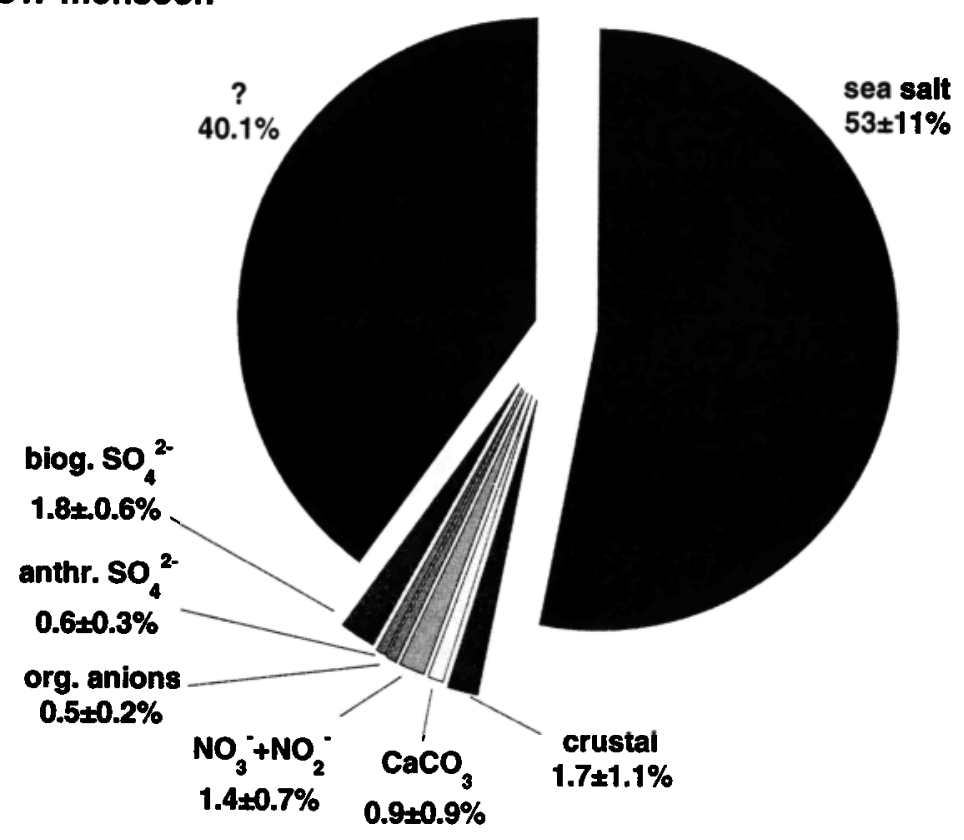

Figure 11. Average relative contribution of major components to total suspended material collected during (a) intermonsoon and (b) SW monsoon.

Tazaki, 1996] and/or formed during transport from in-cloud processing of crustal material [Andreae et al., 1986].

The presence of additional $\mathrm{K}$ and $\mathrm{Mg}$, not accounted for by the sea-salt or the crustal components, may partly be an artifact introduced by assuming an average crustal composition, which may not be representative of this area.

\subsection{Total Suspended Particulates (TSP)}

Total suspended particulates (TSP) are determined on the low-volume filters. The average TSP amounts to $25 \pm 13 \mu \mathrm{g}$ $\mathrm{m}^{-3}$ and $38 \pm 14 \mu \mathrm{g} \mathrm{m}^{-3}$ during the intermonsoon and $\mathrm{SW}$ monsoon, respectively. As depicted in Figures $11 \mathrm{a}$ and $11 \mathrm{~b}$, more than $50 \%$ of the suspended mass during the SW monsoon is sea-salt-derived, while it amounts to $39 \%$ during the intermonsoon, respectively.

The crustal component is determined based on ICP-MS results deduced from the high-volume samples. As indicated in the previous section, sampling efficiencies between the lowand the high-volume collectors vary considerably during strong winds, that is, SW monsoon, and seemingly affecting the larger 
particles more strongly. Thus the crustal component as presented in Figure 11 is an underestimate of what is probably present on the low-volume filters. This low estimate for crustal material during the $\mathrm{SW}$ monsoon amounts to $1.7 \pm 1.1 \%$ of the TSP. The fact that $40 \%$ of the TSP remains unaccounted for indicates that some large crustal particles may not have been collected by the high-volume collector. A similar, less pronounced effect, is observed during the intermonsoon, when $21 \pm 13 \%$ of the TSP appears to be crustal and $17 \%$ remains unattributed.

Gypsum contributions are determined from the outcome of the linear regression analysis that resolved the different $\mathrm{SO}_{4}^{2-}$ sources. The remaining NSS- $\mathrm{Ca}^{2+}$ is assumed to be present as $\mathrm{CaCO}_{3}$. While gypsum was not found during the $\mathrm{SW}$ monsoon, $3.2 \pm 2.1 \%$ of the TSP during the intermonsoon can be attributed to gypsum.

Anthropogenic and biogenic $\mathrm{SO}_{4}^{2-}$ fractions are also extracted from the linear regression analysis, and, when combined, they account for $\sim 7$ and $\sim 2.4 \%$ of the measured TSP during intermonsoon and SW monsoon, respectively. Finally, organic anions, which are also measured by IC from the lowvolume filters, make up only $1.0 \pm 0.7 \%$ of the TSP during the intermonsoon and $0.5 \pm 0.2 \%$ during the SW monsoon.

\section{Conclusions}

Aerosol sampling over the Indian Ocean shows that the intermonsoon period is characterized by strong anthropogenic and crustal signatures, while the SW monsoon is characterized by clean remote marine air masses. Strong winds appear to be responsible for the upwelling of nutrient-rich water near the coast of Oman, which explain the relatively larger biogenically derived MSA concentrations during this season. Linear regression analysis shows that $75 \%$ of NSS-SO ${ }_{4}^{2-}$ is of biogenic origin during the SW monsoon, while during the intermonsoon this number falls to $21 \%$. In addition to an anthropogenic component of NSS-SO $\mathrm{S}_{4}^{2-}$ during both seasons (intermonsoon: $65 \%$, SW monsoon: $8 \%$ ), gypsum is found to be present in the intermonsoon samples. If this added gypsum contribution (14\%) to the total $\mathrm{SO}_{4}^{2-}$ had not been detected, the additional $\mathrm{SO}_{4}^{2-}$ would have been assumed to be of biogenic origin.

Multiple linear regression analyses show that $\mathrm{NO}_{3}^{-}$is not a conservative tracer for anthropogenic- $\mathrm{SO}_{4}^{2-}$ during the intermonsoon; however, $\mathrm{Pb}$ correlates highly with anthr- $\mathrm{SO}_{4}^{2-}$. The observed bio-SO ${ }_{4}^{2-} / \mathrm{MSA}$ weight ratios are as follows: $17.7 \pm$ 4.8 during the intermonsoon at $28.9 \pm 0.6^{\circ} \mathrm{C} ; 13.5 \pm 4.4$ during the $\mathrm{SW}$ monsoon at $27.2 \pm 1.3^{\circ} \mathrm{C}$; and $6.8 \pm 0.5$ in the upwelling region during the $\mathrm{SW}$ monsoon at $24.0 \pm 1.7^{\circ} \mathrm{C}$. An attempt is made in defining a simple temperature dependence for the bio- $\mathrm{SO}_{4}^{2-} / \mathrm{MSA}$ ratio. Although a series of other variables may influence this ratio, the observed temperature dependence is in agreement with that proposed by Hynes et al. [1986]: an increase in the ratio with temperature. Comparable data by Saltzman et al. [1985, 1983] display slightly larger ratios, since the data were not corrected for background $\mathrm{SO}_{4}^{2-}$.

The chloride depletion observed in the samples seems to indicate that during the SW monsoon, $\mathrm{Cl}^{-}$is released in the form of reactive $\mathrm{Cl}$ species in agreement with evidence from a number of investigators [Finlayson-Pitts, 1983; Finlayson-Pitts et al., 1989; Graedel and Keene, 1995; Keene et al., 1990; Pszenny et al., 1993; Vogt et al., 1996]. Reactive $\mathrm{Cl}$ is believed to initiate photochemical reactions in an analogous manner to $\mathrm{OH}$ which would have major consequences for the oxidation of hydrocar- bons and DMS, as proposed by several studies [Keene et al., 1996, 1990; Langer et al., 1996; Pszenny et al., 1993; Sander and Crutzen, 1996; Stickel et al., 1992; Vogt et al., 1996]. However, our results appear to indicate no apparent differential effect in the yield of bio-SO $\mathrm{SO}_{4}^{2-}$ and MSA as a function of $\mathrm{Cl}$ chemistry in the marine boundary layer.

Acknowledgments. The authors wish to thank Meinrat $O$. Andreae and Hermann W. Bange of the Max Planck Institute of Biogeochemistry in Mainz, Germany, for assistance with the Meteor 32/3 and 32/5 cruises, which were sponsored by the German Joint Global Ocean Flux Study (JGOFS) project. Appreciation is also extended to the helpful and lively crew of the R/V Meteor. Research support was provided by the National Science Foundation and by the Environment Now Foundation. Their support is greatly appreciated.

\section{References}

Allen, A. G., A. L. Dick, and B. M. Davidson, Sources of atmospheric methanesulphonate, non-sea-salt sulphate, nitrate and related species over the temperate South Pacific, Atmos. Environ., 31(2), 191205, 1997.

Andreae, M. O., and P. J. Crutzen, Atmospheric aerosols: Biogeochemical sources and role in atmospheric chemistry, Science, 276, 1052-1058, 1997.

Andreae, M. O., R. J. Charlson, H. S. Bruynseels, R. Van Grieken, and W. Maenhaut, Internal mixture of sea salt, silicates, and excess sulfate in marine aerosols, Science, 232, 1620-1623, 1986.

Andreae, M. O., W. Elbert, and S. J. de Mora, Biogenic sulfur emissions and aerosols over the tropical South Atlantic, 3, Atmospheric dimethylsulfide, aerosols, and cloud condensation nuclei, J. Geophys. Res., 100, 11,335-11,356, 1995.

Ayers, G. P., J. M. Cainey, H. Granek, and C. Leck, Dimethylsulfide oxidation and the ratio of methanesulfonate to non sea-salt sulfate in the marine aerosol, J. Atmos. Chem., 25, 307-325, 1996.

Bange, H. W., S. Rapsomanikis, and M. O. Andreae, Nitrous oxide emissions from the Arabian Sea, Geophys. Res. Lett., 23(22), 3175$3178,1996$.

Barone, S. B., A. A. Turnipseed, and A. R. Ravishankara, Role of adducts in the atmospheric oxidation of dimethyl sulfide, Faraday Discuss., 100, 39-54, 1995.

Barone, S. B., A. A. Turnipseed, and A. R. Ravishankara, Reaction of $\mathrm{OH}$ with dimethyl sulfide (DMS), 1, Equilibrium constant for $\mathrm{OH}+$ DMS reaction and the kinetics of the $\mathrm{OH} \cdot \mathrm{DMS}+\mathrm{O}_{2}$ reaction, $J$. Phys. Chem., 100, 14,694-14,702, 1996.

Barrie, L. A., J. W. Bottenheim, R. C. Schnell, P. J. Crutzen, and R. A. Rasmussen, Ozone destruction and photochemical reactions at polar sunrise in the lower Arctic atmosphere, Nature, 334, 138-141, 1988.

Bassett, M. E., and J. H. Seinfeld, Atmospheric equilibrium model of sulfate and nitrate aerosols, II, Particle size analysis, Atmos. Environ., 18(6), 1163-1170, 1984.

Bates, T. S., J. A. Calhoun, and P. K. Quinn, Variations in the methanesulfonate to sulfate molar ratio in submicrometer marine aerosol particles over the South Pacific Ocean, J. Geophys. Res., 97, 98599865, 1992.

Berresheim, H., M. O. Andreae, G. P. Ayers, and R. W. Gillett, Distribution of Biogenic Sulfur Compounds, ACS Symp. Ser., vol. 393, pp. 352-366, Am. Chem. Soc., Washington, D. C., 1989.

Berresheim, H., M. O. Andreae, G. P. Ayers, R. W. Gillett, J. T. Merrill, V. J. Davis, and W. L. Chameides, Airborne measurements of dimethylsulfide, sulfur dioxide, and aerosol ions over the Southern Ocean south of Australia, J. Atmos. Chem., 10, 341-370, 1990.

Berresheim, H., M. O. Andreae, R. L. Iverson, and S. M. Li, Seasonal variations of dimethylsulfide emissions and atmospheric sulfur and nitrogen species over the western North Atlantic Ocean, Tellus, Ser. $B, 43$, 353-372, 1991.

Berresheim, H., F. L. Eisele, D. J. Tanner, L. M. McInnes, D. C. Ramsey-Bell, and D. S. Covert, Atmospheric sulfur chemistry and cloud condensation nuclei (CCN) concentrations over the northeastern Pacific coast, J. Geophys. Res., 98, 12,701-12,711, 1993.

Berresheim, H., P. Wine, and D. Davis, Sulfur in the atmosphere, in Composition, Chemistry, and Climate of the Atmosphere, edited by $\mathrm{H}$. Singh, pp. 251-307, Van Nostrand Reinhold, New York, 1995. 
Bottenheim, J. W., L. A. Barrie, E. Atlas, L. E. Heidt, H. Niki, R. A. Rasmussen, and P. B. Shepson, Depletion of lower tropospheric ozone during Arctic spring: The polar sunrise experiment 1988, $J$. Geophys. Res., 95, 18,555-18,568, 1990.

Bürgermeister, S., and H.-W. Georgii, Distribution of methanesulfonate, nss-sulfate and dimethylsulfide over the Atlantic and the North Sea, Atmos. Environ., Part A, 25(3/4), 587-595, 1991.

Charlson, R. J., J. E. Lovelock, M. O. Andreae, and S. G. Warren, Oceanic phytoplankton, atmospheric sulphur, cloud albedo and climate, Nature, 326, 655-661, 1987.

Chin, M., D. J. Jacob, G. M. Gardner, M. S. Foreman-Fowler, and P. A. Spiro, A global three-dimensional model of tropospheric sulfate, J. Geophys. Res., 101, 18,667-18,690, 1996.

Cruz, C. N., and S. N. Pandis, The effect of organic coatings on the cloud condensation nuclei activation of organic atmospheric aerosols, J. Geophys. Res., 103, 13,111-13,123, 1998.

Duce, R. A., and E. J. Hoffmann, Chemical fractionation at the air/sea interface, Annu. Rev. Earth Planet. Sci., 4, 187-228, 1976.

Duce, R. B., W. H. Zoller, and J. L. Moyers, Particulate and gaseous halogens in the Antarctic atmosphere, J. Geophys. Res., 78, 7802$7811,1973$.

Esteve, V., J. Rius, L. E. Ochando, and J. M. Amigó, Quantitative $\mathrm{X}$-ray diffraction phase analysis of coarse airborne particulate collected by cascade impactor sampling, Atmos. Environ., 31(23), 39633967, 1997.

Fan, S.-M., and D. J. Jacob, Surface ozone depletion in Arctic spring sustained by bromine reactions on aerosol, Nature, 359, 522-524, 1992.

Faust, B. C., and R. G. Zepp, Photochemistry of aqueous iron(III)polycarboxylate complexes: Roles in the chemistry of atmospheric and surface waters, Environ. Sci. Technol., 27, 2517-2522, 1993.

Findlater, J., A major low-level air current near the Indian Ocean during the northern summer, $Q . J . R$. Meteorol. Soc., 95, 362-380, 1969.

Finlayson-Pitts, B. J., Reaction of $\mathrm{NO}_{2}$ with $\mathrm{NaCl}$ and atmospheric implications of $\mathrm{NOCl}$ formation, Nature, 306, 676-677, 1983.

Finlayson-Pitts, B. J., M. J. Ezell, and J. N. Pitts Jr., Formation of chemically active chlorine compounds by reactions of atmospherıc $\mathrm{NaCl}$ particles with gaseous $\mathrm{N}_{2} \mathrm{O}_{5}$ and $\mathrm{ClONO}_{2}$, Nature, 337, 241244, 1989.

Gao, Y., R. Arimoto, R. A. Duce, L. Q. Chen, M. Y. Zhou, and D. Y. $\mathrm{Gu}$, Atmospheric non-sea-salt sulfate, nitrate, and methanesulfonate over the China Sea, J. Geophys. Res., 101, 12,601-12,611, 1996.

Graedel, T. E., and W. C. Keene, Tropospheric budget of reactive chlorine, Global Brogeochem. Cycles, 9(1), 47-77, 1995.

Graedel, T. E., and W. C. Keene, The budget and cycle of Earth's natural chlorine, Pure Appl. Chem., 68(9), 1689-1697, 1996.

Hoornaert, S., H. van Malderen, and R. van Grieken, Gypsum and other calcium-rich aerosol particles above the North Sea, Environ. Sci. Technol., 30, 1515-1520, 1996.

Hopke, P. K., Appendix: Selected source profiles, in Receptor Modeling in Environmental Chemistry, pp. 267-314, John Wiley, New York, 1985.

Huebert, B. J., L. Zhuang, S. Howell, K. Noone, and B. Noone, Sulfate, nitrate, methanesulfonate, chloride, ammonium, and sodium measurements from ship, island, island, and aircraft during the Atlantic Stratocumulus Transition Experiment/Marıne Aerosol Gas Exchange, J. Geophys Res., 101, 4413-4423, 1996.

Hynes, A. J., P. H. Wine, and D. H. Semmes, Kinetics and mechanism of $\mathrm{OH}$ reactions with organic sulfides, J. Phys. Chem., 90, 4148$4156,1986$.

Kawamura, K., and K. Ikushima, Seasonal changes in the distribution of dicarboxylic acids in the urban atmosphere, Environ. Sci. Technol., $27,2227-2235,1993$.

Keene, W. C., A. A. P. P‘zenny, J. N. Galloway, and M. E. Hawley. Sea-salt corrections and interpretation of constituent ratios in marine precipitation, J. Geophys. Res., 91, 6647-6658, 1986.

Keene, W. C., A. A. P. Pszenny, D. J. Jacob, R. A. Duce, J. N. Galloway, J. J. Schultz-Tokos, H. Sievering, and J. F. Boatman, The geochemical cycling of reactive chlorine through the marıne troposphere, Global Biogeochem. Cycles, 4(4), 407-430, 1990.

Keene, W. C., D. J. Jacob, and S.-M. Fan, New directions: Reactive chlorine: A potential sink for dimethylsulfide and hydrocarbons in the marine boundary layer, Atmos. Envtron., 30(6), 1-3, 1996.

Keene, W. C., R. Sander, A. A. P. Pszenny, R. Vogt, P. J. Crutzen, and
J. N. Galloway, Aerosol $\mathrm{pH}$ in the marine boundary layer: A review and model evaluation, J. Aerosol Sci., 29(3), 339-356, 1998.

Kerminen, V.-M., R. E. Hillamo, and A. S. Wexler, Model simulations on the variability of particulate MSA to non-sea-salt sulfate ratio in the marine atmosphere, J. Atmos. Chem., 30, 345-370, 1998a.

Kerminen, V.-M., K. Teinilä, R. Hillamo, and T. Pakkanen, Substitution of chloride in sea-salt particles by inorganic and organic anions, J. Aerosol Sci., 29(8), 929-942, 1998 b.

Koga, S., and H. Tanaka, Simulations of seasonal variations of sulfur compounds in the remote marine atmosphere, J. Atmos. Chem., 23, 163-192, 1996.

Langer, S., B. T. McGovney, B. J. Finlayson-Pitts, and R. M. Moore, The dimethyl sulfide reaction with atomic chlorine and its implications for the budget of methyl chloride, Geophys. Res. Lett., 23(13), 1661-1664, 1996.

Martin, J. H., and S. F. Fitzwater, Iron deficiency limits phytoplankton growth in the northeast Pacific subarctic, Nature, 331, 341-342, 1988.

Martin, J. H., R. M. Gordon, and S. E. Fitzwater, The case of iron, Limnol. Oceanogr., 36(8), 1793-1802, 1991.

Martin, J. H., et al., Testing the iron hypothesis in ecosystems of the equatorial Pacific Ocean, Nature, 371, 123-129, 1994.

Matsumoto, K., H. Tanaka, I. Nagao, and Y. Ishizaka, Contribution of particulate sulfate and organic carbon to cloud condensation nuclei in the marine atmosphere, Geophys. Res. Lett., 24(6), 655-658, 1997.

McConnell, J. C., G. S. Henderson, L. Barrie, J. Bottenheim, H. Niki, C. H. Langford, and E. M. J. Templeton, Photochemical bromine production implicated in Arctic boundary-layer ozone depletion, Nature, 355, 150-152, 1992.

McInnes, L. M., D. S. Covert, P. K. Quinn, and M. S. Germani, Measurements of chloride depletion and sulfus enrichment in individual sea-salt particles collected from the remote marine boundary layer, J. Geophys. Res., 99, 8257-8268, 1994.

Millero, F. J., and M. L. Sohn, Chemical Oceanography, CRC Press, Boca Raton, Fla., 1992

Naik, M. S., L. T. Khemani, G. A. Momin, P. S. Prakasa Rao, and P. D. Safai, Origin of calcium in marine aerosol over the Arabian Sea near the west coast of India, J. Aerosol Sci., 22(3), 365-372, 1991.

Novakov, T., and J. E. Penner, Large contribution of organic aerosols to cloud-condensation nuclei concentrations, Nature, 365, 823-826, 1993.

O'Dowd, C., M. H. Smith, I. E. Consterdine, and J. A. Lowe, Marine aerosol, sea-salt, and the marine sulphur cycle: A short review, Atmos. Environ., 31(1), 73-80, 1997.

Patroescu, I. V., I. Barnes, K. H. Becker, and N. Mihalopoulos, FT-IR product study of the $\mathrm{OH}$-initiated oxidation of DMS in the presence of $\mathrm{NO}_{x}$, Atmos. Environ., 33, 25-35, 1999.

Pehkonen, S. O., R. Siefert, Y. Erel, S. Webb, and M. Hoffmann, Photoreduction of iron oxyhydroxides in the presence of important atmospheric organic compounds, Environ. Sct. Technol., 27(10), 2056-2062, 1993.

Prospero, J. M., D. L. Savoie, E. S. Saltzman, and R. Larsen, Impact of oceanic sources of biogenic sulphur on sulphate aerosol concentrations at Mawson, Antarctica, Nature, 350, 221-223, 1991.

Pszenny, A. A. P., A. J. Castelle, and J. N. Galloway, A study of the sulfur cycle in the Antarctic marıne boundary layer, J. Geophys. Res., 94, 9818-9839, 1989.

Pszenny, A. A. P., W. C. Keene, D. J. Jacob, S. Fun, J. R. Maben, M. P. Zetwo, M. Springer-Young, and J. N. Galloway, Evidence of inorganic chlorine gases other than hydrogen chloride in marine surface air, Geophys. Res. Le't.. 2()(8), 699-702, 1993.

Saltzman, E. S., D. L. Savole, R. G. Zıka, and J. M. Prospero, Methane sulfonic acid in the marıne atmosphere, J. Geophys. Res., 88, 10,897$10,902,1983$.

Saltzman, E. S., D. L. Savoie, J. M. Prospero, and R. G. Zıka, Atmospheric methanesulfonic acid and non-sea-salt sulfate at Fanning and American Samoa, Geophys. Res. Lett., 12(7), 437-440, 1985.

Sander, R., and P. J. Crutzen, Model study indicating halogen activation and ozone destruction in polluted air masses transported to the sea, J. Geophys. Res., 101, 9121-9138, 1996.

Savoie, D. L., and J. M. Prospero, Particle size distribution of nitrate and sulfate in the marine atmosphere, Geophys. Res. Lett., 9(10), $1207-1210,1982$

Savoie, D. L., and J. M. Prospero, Comparison of oceanic and continental sources of non-sea-salt sulphate over the Pacific Ocean, $\mathrm{Na}$ ture, 339, 685-687, 1989. 
Savoie, D. L., and J. M. Prospero, Non-sea-salt sulfate and methansulfonate at American Samoa, J. Geophys. Res., 99, 3587-3596, 1994.

Savoie, D. L., J. M. Prospero, and R. T. Nees, Nitrate, non-sea-salt sulfate, and mineral aerosol over the northwestern Indian Ocean, $J$. Geophys. Res., 92, 933-942, 1987.

Savoie, D. L., J. M. Prospero, and E. S. Saltzman, Non-sea-salt sulfate and nitrate in trade wind aerosols at Barbados: Evidence for longrange transport, $J$. Geophys. Res., 94, 5069-5080, 1989.

Savoie, D. L., J. M. Prospero, R. J. Larsen, and E. S. Saltzman, Nitrogen and sulfur species in aerosols at Mawson, Antarctica, and their relationship to natural radionuclides, J. Atmos. Chem., 14, 181-204, 1992.

Schlesinger, W. H., and A. E. Hartley, A global budget for atmospheric $\mathrm{NH}_{3}$, Biogeochemistry, 15, 191-211, 1992.

Siefert, R. L., S. O. Pehkonen, Y. Erel, and M. R. Hoffmann, Iron photochemistry of aqueous suspensions of ambient aerosol with added organic acids, Geochim. Cosmochim. Acta, 58(15), 3271-3279, 1994.

Siefert, R. L., A. M. Johansen, and M. R. Hoffmann, Chemical characterization of ambient aerosol collected during the southwest and intermonsoon seasons over the Arabian Sea: Labile-Fe(II) and other trace metals, J. Geophys. Res., 104, 3511-3526, 1999.

Sievering, H., G. Ennis, E. Gorman, and C. Nagamoto, Size distribution and statistical analysis of nitrate, excess sulfate, and chloride deficit in the marine boundary layer during GCE/CASE/WATOX, Global Biogeochem. Cycles, 4(4), 395-405, 1990.

Sisterson, D. L., A method for evaluation of acidic sulfate and nitrate in precipitation, Water Air Soil Pollut., 43, 61-72, 1989.

Sørensen, S., H. Falbe-Hansen, M. Mangoni, J. Hjorth, and N. R. Jensen, Observation of DMSO and $\mathrm{CH}_{3} \mathrm{~S}(\mathrm{O}) \mathrm{OH}$ from the gas phase reaction between DMS and OH, J. Atmos. Chem., 24, 299-315, 1996.

Statistical Product and Service Solutions (SPSS), SPSS for Windows, SPSS Inc., Chicago, Ill., 1997.

Stickel, R. E., J. M. Nicovich, Z. Zhao, and P. H. Wine, Kinetic and mechanistic study of the reaction of atomic chlorine with dimethyl sulfide, J. Phys. Chem., 96, 9875-9883, 1992.

Sturges, W. T., and L. A. Barrie, Chlorine, bromine and iodine in Arctic aerosols, Atmos. Environ., 22(6), 1179-1194, 1988.

Sturges, W. T., and G. E. Shaw, Halogens in aerosol in central Alaska, Atmos. Environ., Part A, 27(17/18), 2969-2977, 1993.
Taylor, S. R., and S. M. McLennan, The Conttnental Crust: Its Composition and Evolution, Blackwell Sci., Cambridge, Mass., 1985.

Turnipseed, A. A., and A. R. Ravishankara, The atmospheric oxidation of dimethyl sulfide: Elementary steps in a complex mechanism, in Dimethylsulfide: Oceans, Atmosphere and Climate, edited by G. R. A. G. Angeletti, pp. 185-196, Kluwer Acad., Norwell, Mass., 1993.

Turnipseed, A. A., S. B. Barone, and A. R. Ravishankara, Reaction of $\mathrm{OH}$ with dimethyl sulfide, 2, Products and mechanism, J. Phys. Chem., 100, 14,703-14,713, 1996.

van Malderen, H., R. van Grieken, T. Khodzher, V. Obolkin, and V. Potemkin, Composition of individual aerosol particles above Lake Baikal, Siberia, Atmos. Environ., 30(9), 1453-1465, 1996.

Vogt, R., P. J. Crutzen, and R. Sander, A mechanism for halogen release in the remote marine boundary layer, Nature, 383, 327-330, 1996.

Yin, F., D. Grosjean, and J. H. Seinfeld, Analysis of atmospheric photooxidation mechanisms for organosulfur compounds, J. Geophys. Res., 91, 14,417-14,438, 1986.

Yin, F., D. Grosjean, and J. H. Seinfeld, Photooxidation of dimethyl sulfide and dimethyl disulfide, I, Mechanism development, J. Atmos. Chem., 11, 309-364, 1990.

Zar, J. H., Biostatistical Analysis, Prentice-Hall, Englewood Cliffs, N. J., 1996.

Zhou, G., and K. Tazaki, Seasonal variation of gypsum in aerosol and its effect on the acidity of wet precipitation on the Japan Sea side of Japan, Atmos. Environ., 30(19), 3301-3308, 1996.

M. R. Hoffmann (corresponding author) and A. M. Johansen, Environmental Engineering Science, W. M. Keck Laboratories, California Institute of Technology, Pasadena, CA 91125. (mrh@cco. caltech.edu)

R. L. Siefert, Chesapeake Biological Laboratory, University of Maryland Center for Environmental Science, P.O. Box 38, One Williams Street, Solomons, MD 20688.

(Received February 9, 1999; revised May 6, 1999; accepted June 9, 1999.) 